\title{
Hydroxyl Identification on ZnO by Infrared Spectroscopies: Theory and Experiments
}

\author{
Francesc Viñes, ${ }^{*}, 1$ Ana Iglesias-Juez, ${ }^{2}$ Francesc Illas, ${ }^{1}$ and Marcos Fernández-García ${ }^{* 2}$ \\ ${ }^{I}$ Departament de Química Fisica \& Institut de Quimica Teòrica i Computacional (IQTCUB), \\ Universitat de Barcelona, c/Martí i Franquès 1,08028 Barcelona, Spain. \\ 2 Instituto de Catálisis y Petroleoquímica, CSIC, c/Marie Curie 2, Cantoblanco, 28049 Madrid, \\ Spain. \\ *corresponding authors: francesc.vines@ub.edu, $\underline{\operatorname{mfg} @ \text { icp.csic.es }}$
}

\begin{abstract}
Here we present a thorough density functional study combining experiments on $\mathrm{ZnO}$ nanostructures aimed at the identification, by means of Infrared $(I R)$ spectroscopies, of hydroxyl and hydride species formed on most stable low-index Miller surfaces of würtzite

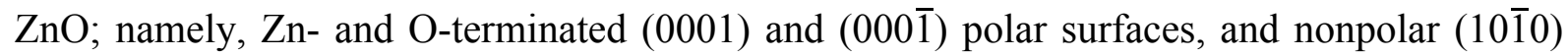
and $(11 \overline{2} 0)$ surfaces. The Perdew-Burke-Ernzerhof functional was employed on the periodic slab calculations, and all possible $\mathrm{H}$ and $\mathrm{OH}$ adsorption modes were studied at medium and full coverage, while IR spectra were simulated for most favourable situations. This information was used to model the most likely surface arrangements when exposed to either $\mathrm{H}_{2}$ or $\mathrm{H}_{2} \mathrm{O}$. IR experiments on $\mathrm{ZnO}$ surfaces and nanoparticles are discussed based on the calculated adsorption energy values and simulated IR spectra. The study emphasizes the detailed assignment of $\mathrm{OH}$ moieties with the help of IR and their interpretation as fingerprints of surface morphology, allowing for a consistent interpretation of water adlayers stability and their corresponding vibrational fingerprints as a function of coverage, low-index Miller surface, and hydrogen source.
\end{abstract}

Keywords: density functional calculations • IR spectroscopy • catalysis • surface hydroxyls • würtzite $\mathrm{ZnO}$ 


\section{Introduction}

Würtzite Zinc Oxide (or zinczite) is a material that has driven very much research interest in the last decades, mostly due to its optical and electronic properties. It displays high electron mobility and thermal conductivity, and a direct bandgap $(\sim 3.4 \mathrm{eV})$ with large exciton binding energies $(\sim 60 \mathrm{meV}) .{ }^{1,2}$ These properties have spurred its usage in semiconductors, ${ }^{3}$ field-effect transistors, ${ }^{4}$ photodetectors, ${ }^{5}$ blue- and ultraviolet-light ( $U V$-light) emitting and laser diodes, ${ }^{6,7}$ gas sensors, ${ }^{8}$ piezoelectric generators, ${ }^{9}$ transparent electrodes, ${ }^{10}$ and cells for solar light harvesting. ${ }^{11,12}$

In chemistry, $\mathrm{ZnO}$ has recently become the focus of many researches addressing its usage as a catalyst for a variety of reactions; from being an active phase in methanol synthesis using the ternary Copper-based $\mathrm{Cu} / \mathrm{ZnO} / \mathrm{Al}_{2} \mathrm{O}_{3}$ catalyts, ${ }^{13-15}$ to water ${ }^{16}$ and sulphur hydride ${ }^{17}$ dissociations, desulfurization processes, ${ }^{18,19}$ the water gas shift reaction, ${ }^{20}$ the activation of $\mathrm{CO}_{2},{ }^{21}$ and finally, the conversion of maleic anhydride into 1,4-butanediol. ${ }^{22}$ Furthermore, the above-commented UV-light absorption capability has unfolded its use in light-triggered catalysis, such as for dye decomposition, ${ }^{23,24}$ the treatment of volatile organic compounds, ${ }^{25}$ the peroxide synthesis, ${ }^{26}$ water splitting, ${ }^{27}$ and alcohol photodegradation. ${ }^{28,29}$

Nevertheless, these catalytic or photocatalytic processes are far from being well understood and efficiently mastered, and the aspects on which the catalytic activity and selectivity hang are still a matter of debate. Many experimental works have addressed the point by relating the catalytic activity with structural factors, this is sampling a variety of $\mathrm{ZnO}$ morphologies -including single crystal surfaces, ${ }^{30}$ thin films, ${ }^{24}$ nanostructures, ${ }^{31,32}$ and wellfaceted nanoparticles ${ }^{23,33}$ - with distinct polar/nonpolar facet ratios. This proportion is often argued to be a key aspect on the photochemical catalytic activity: Some working groups

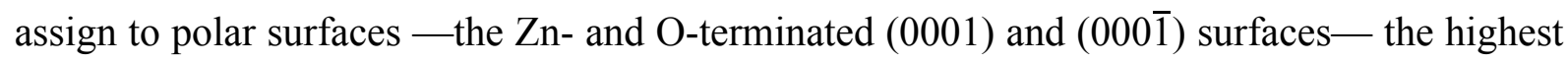


catalytic activity, ${ }^{23,31}$ whereas other point to nonpolar surfaces - the $(10 \overline{1} 0)$ and $(11 \overline{2} 0)$ surfaces. $^{30}$

Along this line there is also an open discussion on the role of surface hydroxyl and hydride species on most of the aforementioned catalysed reactions. This is because in many of them one or more reaction steps involve hydrogenation/dehydrogenation of reaction species, likely to be carried out by these surface moieties. ${ }^{34}$ For instance, previous works pinpoint that the hydroxyl scavenger character of isopropanol is decisive in its degradation. ${ }^{35,36}$ In another related study, the pivotal role of acid/basic sites on the catalytic activity and specificity is highlighted. ${ }^{37}$ Indeed, in many of the commented processes either heterolytic dissociation of $\mathrm{H}_{2}$ or water splitting is actually considered the rate-determining step.

Clearly, the unambiguous identification of the reacting hydroxyl or hydride species under working conditions is vital for the real-time observation of the catalytic process and the outline of the reaction mechanism, eventually allowing for a posterior improvement of the reaction setup. This is usually experimentally tackled by a combination of spectroscopic and microscopy techniques. Vibrational spectroscopies can be highlighted as prototypical techniques among them due to their (experimental and theoretical) simplicity and potential use in all conditions (e.g. ex and/or in situ conditions), providing additionally information of the conformation and bond strengths of surface species with direct relation to surface/catalytic phenomena. ${ }^{38,39}$ However the assignment of the vibrational fingerprints is by no means easy, and often assumptions based on common knowledge - e.g. vibrational fingerprints of transition metal complexes - drive to misassignments and, therefore, to erroneous

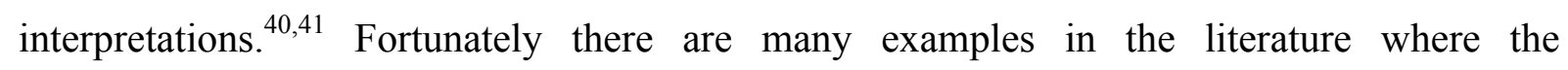
combination of Infrared (IR) spectroscopies under controlled conditions and Density Functional $(D F)$ calculations on proper models solved the problematic and permitted the unequivocal assignment of complex vibrational features. ${ }^{40,42,43}$ 
In the case of würtzite $\mathrm{ZnO}$ there is quite a number of recent experimental studies aimed at this issue. It is worth to highlight the paramount works of Wang et al. using High-

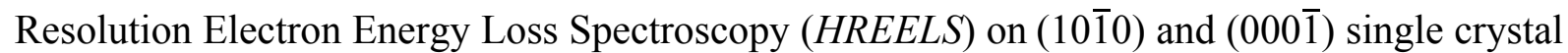
surfaces, ${ }^{44-46}$ and the recent studies of Noei et al. applying Fourier Transform Infrared Spectroscopy $(F T I R)$ or Diffusive Reflectance Infrared Fourier Transform Spectroscopy (DRIFTS) on $\mathrm{ZnO}$ nanoparticles. ${ }^{34,47}$ In both research lines assignments of different features to specific surface hydroxyl or hydride groups are posed, yet some surfaces remain unexplored, and even the studied assignment seems to contradict earlier and recent experiments. ${ }^{34,48-50}$ From the theoretical point of view the matter is far more shaky. Despite there is also a number of DF studies addressing the structure and stabilization mechanisms of the bespoken surfaces saturated with either water or hydrogen, ${ }^{51-55}$ these computational studies did not address their vibrational identification. To the best of our knowledge, there is no previous DF theoretical study consistently addressing the assignment of vibrational spectroscopy features to surface hydride or hydroxyl moieties when exposing $\mathrm{ZnO}$ systems to either $\mathrm{H}_{2}$ or $\mathrm{H}_{2} \mathrm{O}$.

In the present work we study, by means of state-of-the-art DF calculations on proper slab models, the stability of polar $-(0001)$ and $(000 \overline{1})$ - and nonpolar $-(10 \overline{1} 0)$ and $(11 \overline{2} 0)$ - surfaces of würtzite $\mathrm{ZnO}$ exposed to $\mathrm{H}_{2}$ or $\mathrm{H}_{2} \mathrm{O}$. Simulated IR vibrational spectra are gained for the most stable surface adsorbate arrangements as a function of coverage and hydrogen source. A full analysis of hydroxyl-related species at surface model systems as well as on $\mathrm{ZnO}$ nanoparticles is presented.

\section{Methodology}

\subsection{Computational Details and Models}

Current DF calculations were performed with the VASP code, ${ }^{56}$ carrying out periodic Kohn-Sham calculations. The projector augmented wave method has been used to represent 
the atomic cores, ${ }^{57}$ allowing for obtaining converged results — variations in energy below $0.01 \mathrm{~kJ} \mathrm{~mol}^{-1}$ - with a cut-off kinetic energy of $415 \mathrm{eV}$ for the plane-wave basis set. Geometry optimizations were performed using a conjugated gradient algorithm and applying a tetrahedron smearing method with Blöchl corrections with a $0.2 \mathrm{eV}$ width, although final energy values were corrected to $0 \mathrm{~K}$ (no smearing). The structural optimization was finalized when forces acting on atoms were below $0.01 \mathrm{~kJ} \mathrm{~mol}^{-1} \mathrm{pm}^{-1}$. Unless stated otherwise, all calculations were carried out in a non spin-polarization fashion. All DF calculations have been carried out using the Perdew-Burke-Erzenhof $(P B E)$ exchange correlation functional, ${ }^{58}$ proven to deliver a realistic description of bulk $\mathrm{ZnO}$ and low-index Miller surfaces, ${ }^{59,60}$ as well as to properly capture the interactions of atomic hydrogen, hydroxyl moieties, and water molecules upon. ${ }^{16,61}$

From previous X-Ray Diffraction $(X R D)$ studies $^{11,23,25,29,32}$ it is clear that würtzite $\mathrm{ZnO}$ preferentially displays the nonpolar $(10 \overline{1} 0)$ and (1120) surfaces, and the $\mathrm{Zn}$ - and O-terminated $(0001)$ and $(000 \overline{1})$ polar surfaces. The latter ones are simultaneously created when cutting the crystal along a basal plane, see Figure 1. Nonpolar surfaces exhibit perfectly stable unreconstructed terminations. Polar surfaces feature a surface energy instability issue originated from their different charged terminations, which exert a net dipole moment that, de facto, increases with the separation between them. This introduces an electrostatic component to the surface energy which diverges with the surface separation. ${ }^{62,63}$ The stabilization mechanisms to nullify this dipole moment are nowadays a hot topic, with some experiments suggesting the existence of unreconstructed polar surfaces, ${ }^{64}$ implying a charge transfer among the two polar surfaces, ${ }^{59,64,65}$ whereas other studies suggesting the formation of vacancies regularly found on the surface, ${ }^{66,67}$ or concentrated at step edges. ${ }^{51,53}$

Regardless of the previous, when fully hydrogenated/hydrated both polar surfaces show a perfect $(1 \times 1)$ arrangement with apparently no surface vacancies. ${ }^{67,68}$ Moreover, unreconstructed polar surfaces can be perfectly stable in oxide nanoparticles. Thus, we 
decided to use unreconstructed and vacant-free surface supercell slab models to simulate $\mathrm{ZnO}$ single crystals and the facets of nanoparticles. Last but not least, note that when fully hydrogenated/hydrated, nonpolar surfaces also display a $(1 \times 1)$ periodicity —with the caveat of $\mathrm{H}_{2} \mathrm{O}$ on $(10 \overline{1} 0)$ which, according to previous simulations and experiments, may display a $(2 \times 1)$ pattern. ${ }^{16,69}$

Towards this end, 8-layer slab — constructed from the orthogonal unit cell instead of the primitive hexagonal unit cell, see Figure $1-(1 \times 1)$ supercell models have been used for each of the four surfaces, in which the upmost four layers are completely allowed to relax, and the bottommost four layers are kept fixed as in the bulk-optimized positions. Note that cell contains a single surface $\mathrm{ZnO}$ pair for the (1010) surface, but two units for polar and $(11 \overline{2} 0)$ surfaces. To correctly study the $(10 \overline{1} 0)$ surface a $(2 \times 1)$ unit cell has been used when needed. Present tests and several past studies reveal that the employed slab width and relaxation approximation is enough to ensure converged results of surface properties, ${ }^{52,59-}$ 61,64,65,70-72 except for cleavage energies of polar surfaces, which should be derived with an extrapolation to infinite slab thickness. ${ }^{52,59,60,64}$

A minimum vacuum of $1 \mathrm{~nm}$ was applied in the surface direction to avoid interaction between repeated slabs. Optimized slabs with larger vacuum gap showed deviations in the total energy below $0.02 \mathrm{~kJ} \mathrm{~mol}^{-1}$. To compensate the long-range dipole-dipole interactions among translationally repeated slabs a counterdipole is placed in the middle of the vacuum gap. An optimal Monkhorst-Pack k-points grid of $17 \times 17 \times 1$ has been used for the $\mathrm{ZnO}$ surface calculations. This guarantees a convergence of the energy to values below $0.01 \mathrm{~kJ} \mathrm{~mol}^{-1}$ as tested using denser grids.

The adsorption energy, $E_{a d s}$, of a species $\mathrm{A}-\mathrm{H}_{2} \mathrm{O}, \mathrm{OH}$, or $\mathrm{H}-$ on a substrate B either the polar $(0001)$ or $(000 \overline{1})$ surfaces, or the nonpolar $(10 \overline{1} 0)$ or $(11 \overline{2} 0)$ surfaces - is defined according to the following equation; 


$$
E_{a d s}=-E_{A / B}+\left(E_{A}+E_{B}\right)
$$

where $E_{A / B}$ is the energy of the complete system where $\mathrm{A}$ is adsorbed on the surface $\mathrm{B}$, and $E_{A}$ and $E_{B}$ are the energies of the isolated species $\mathrm{A}$ and surface $\mathrm{B}$, respectively. Note that with this definition the adsorption energy is positive if the adsorbate is bound to the substrate, with larger adsorption energy indicating stronger bonding. $\mathrm{H}_{2}$ is experimentally found to molecularly adsorb on würtzite only below $90 \mathrm{~K}$, and so, it has not been considered as an adsorbate in the present study, as it would be either decomposed or desorbed in normal catalytic conditions. ${ }^{73,74}$ The isolated $\mathrm{H}$ atomic reference and the molecular $\mathrm{OH}$ and $\mathrm{H}_{2} \mathrm{O}$ species were optimized in an asymmetric box of $0.9 \times 1.0 \times 1.1 \mathrm{~nm}^{3}$ dimensions, carrying out $\Gamma$ point spin-polarized calculations for $\mathrm{H}$ and $\mathrm{OH}$ in order to properly describe their doublet character. A Gaussian smearing of $0.01 \mathrm{eV}$ width was applied in these calculations.

Harmonic frequencies were obtained through numerical calculation and diagonalization of the Hessian matrix taking into consideration only the adsorbate molecules and, in the case of atomic $\mathrm{H}$, the surface species it is bonded to. The Hessian matrix is constructed from finite differences of analytical gradients by calculating energy changes due to independent displacements of $3 \mathrm{pm}$ of every atom in each direction of the unit cell vectors. Shorter displacements lead to frequency shifts below $4 \mathrm{~cm}^{-1}$, i.e. below standard experimental resolution. ${ }^{47}$ Negligible coupling with substrate phonons is expected since the latter exhibit distinctive lower frequencies, typically ranging $100-600 \mathrm{~cm}^{-1}$, according to Raman spectroscopies. $^{75-77}$ Test calculations of the adsorbate harmonic frequencies accounting for variables of influence, such as phonon coupling, different k-points grids, and the absence of a counterdipole resulted in frequency variations below $2 \mathrm{~cm}^{-1}$.

Simulated IR spectra have been obtained estimating the intensity of a band through the change of the dipole moment component normal to surface accompanying a given vibration. The spectra have been drawn by smoothing the peaks with a Gaussian function of $100 \mathrm{~cm}^{-1}$ 
half width. This procedure has been widely used in the past for calculations of adsorbate

spectra on solid metal surfaces. ${ }^{40,42,43,78-80}$ There, only vibrations with a dipole component normal to the surface are detected, since the parallel component is cancelled by a specular counterdipole created by the metal surface electron density cloud. On ionic composites such polarization of the electron sea cannot happen, although the electron densities surrounding the atomic nuclei are indeed polarizable to a certain extent, and therefore, given a sufficient material width, they may likewise counteract the parallel component of an adsorbate vibration. This has been experimentally confirmed, e.g. by performing sum frequency generation vibrational spectroscopies of adsorbates on $\mathrm{TiO}_{2}$ and $\mathrm{SiO}_{2},{ }^{81,82}$ here justifying to measure the intensity normal to the surface alone for adsorbate vibrations on oxides.

\subsection{Experimental Details}

Materials were prepared using a microemulsion method using $n$-heptane (Scharlau) as organic media, Triton $\mathrm{X}-100\left(\mathrm{C}_{14} \mathrm{H}_{22} \mathrm{O}\left(\mathrm{C}_{2} \mathrm{H}_{4} \mathrm{O}\right)_{\mathrm{n}}\right)$ (Aldrich) as surfactant and hexanol (Aldrich) as cosurfactant. Zn was introduced from the nitrate from (Aldrich). Water/Zn molar ratio was fixed at 110 and water/surfactant molar ratio was varied from 18 (sample $\mathbf{A}$ ) to 9 (sample B). After introduction of $\mathrm{Zn}$ into the aqueous phase and $30 \mathrm{~min}$ of stirring, a double quantity of tetramethylammonium-hydroxide was introduced from the aqueous phase of a similar microemulsion. The resulting mixture was stirred for $24 \mathrm{~h}$, centrifuged, and the separated solid precursors rinsed with methanol and dried at $110{ }^{\circ} \mathrm{C}$ for $12 \mathrm{~h}$. The BrunauerEmmett-Teller $(B E T)$ surface areas and average pore volume and sizes were measured by nitrogen physisorption (Micromeritics ASAP 2010). Samples present a BET area of 25 and 23 $\mathrm{m}^{2} \mathrm{~g}^{-1}$ for $\mathbf{A}$ and $\mathbf{B}$ materials, respectively.

High-Resolution Transmission Electron Microscopy (HRTEM) was recorded on a JEOL 2100F TEM/STEM microscope. Specimens were prepared by dripping an ethanol suspension of the samples to be investigated onto a copper grid supporting a perforated 
carbon film. Diffuse Reflectance IR spectra were obtained with a Bruker Vertex 80 after overnight treatment at $150{ }^{\circ} \mathrm{C}$ or $350{ }^{\circ} \mathrm{C}$ of the samples under a nitrogen atmosphere. Spectra are an accumulation of 50 spectra (30 seconds each) with a nominal resolution of $4 \mathrm{~cm}^{-1}$. Analysis of the spectra was carried out considering the derivative spectra to extract the number of components. Fitting was performed with the peakfit program using Gaussian shapes for the components.

\section{Results and Discussion}

\subsection{H Adsorption}

First we examined the adequacy of the computing level by analyzing $\mathrm{ZnO}$ bulk and surface properties (see Supporting Information). In summary, a very good agreement is found between present PBE results and most recent experimental bulk structural parameters, ${ }^{83}$ with a slight overestimation of the bond strength per $\mathrm{ZnO}$ unit of $\sim 20 \mathrm{~kJ} \mathrm{~mol}^{-1}$ compared to the experimental value ${ }^{84}$ in the order of standard DF methods accuracy. The relaxed surface structure of $(10 \overline{1} 0)$ is in excellent agreement with very recent aberration-corrected HRTEM images, ${ }^{85}$ and earlier experiments. ${ }^{86-88}$ Additionally, the relaxation of polar $(000 \overline{1})$ surface is also in excellent agreement with structural data derived from Surface XRD (SXRD) and Grazing Incidence X-Ray Diffraction $(G I X D)$ experiments. ${ }^{64,89}$ Thus, we conclude that the employed methodology appears to be suited for the description of the systems under scope.

Concerning the adsorption of species, we tackled firstly the simplest atomic $\mathrm{H}$ adsorption at two different coverages $(\theta)$, this is, at half and full coverage, hereafter also referred as 0.5 and 1 monolayers $(M L)$. All possible adsorption sites on the modeled surfaces have been sampled, yet only the most stable case on each surface is further discussed. For $(000 \overline{1})$ surface only the $\mathrm{H}$ on-top of an $\mathrm{O}$ surface atom $\left(\mathrm{O}_{\mathrm{s}}\right)$ conformation was found. For the other surfaces many situations are possible, although considerably less stable — by at least 30 $\mathrm{kJ} \mathrm{mol}^{-1}$ - and so, not further considered unless explicitly invoked. In all surfaces $\mathrm{H}$ attaches 
to surface $\mathrm{O}$ atoms, with the caveat of the (0001) surface where it attaches on-top of surface Zn atoms forming hydride entities. Structural, energetic, and vibrational calculated data are listed in Table 1, while views of the adsorbed conformations together with their simulated IR spectra are illustrated in Figure 2. Note that when taking $\mathrm{H}_{2}$ molecule in vacuum as the energy reference the adsorption energies shown in Table 1 must be lowered by $218 \mathrm{~kJ} \mathrm{~mol}^{-1}$, accounting for half the dissociation energy of $\mathrm{H}_{2}$. Therefore, adsorption energies larger than this latter value indicate an exothermic $\mathrm{H}_{2}$ adsorption process, and vice versa.

(0001) surface: Values in Table 1 confirms that the polar $(000 \overline{1})$ surface is the most active one for $\mathrm{H}$ adsorption, with large dissociative adsorption energies, especially when $\mathrm{H}$ is adsorbed on-top of every second surface $\mathrm{O}$ atom, i.e. $\theta=0.5 \mathrm{ML}$. Current values match discrepancies of $\sim 4 \mathrm{~kJ} \mathrm{~mol}^{-1}$ — previous PBE results by Meyer, ${ }^{52}$ and support previous claim pointing that the most stable situation for $(000 \overline{1})$ under normal conditions is that forming a $(1 \times 2)$ surface periodic arrangement, ${ }^{52,55}$ recently corroborated based on depth profile X-Ray Photoelectron Spectroscopy $(X P S)$ measurements. ${ }^{55}$ Note that the desorption energy of a $\mathrm{H}_{2}$ molecule at $\theta=0.5 \mathrm{ML}, 388 \mathrm{~kJ} \mathrm{~mol}^{-1}$ —calculated as twice the atomic $\mathrm{H}$ desorption energy reported in Table 1 but accounting for half $\mathrm{H}_{2}$ dissociation energy, as above-commented-, is far larger than that for $\mathrm{H}_{2}$ at $\theta=1 \mathrm{ML}\left(152 \mathrm{~kJ} \mathrm{~mol}^{-1}\right)$. When we compare the adsorption energy per unit cell — proportional as if done per surface area-, the desorption energy at half coverage is $194 \mathrm{~kJ} \mathrm{~mol}^{-1}$ —note that at this coverage two unit cells with an adsorbed $\mathrm{H}$ atom are needed to desorb a $\mathrm{H}_{2}$ molecule — reflecting that more energy is released — about $40 \mathrm{~kJ}$ $\mathrm{mol}^{-1}$ - when covering half of the $(000 \overline{1})$ surface with atomic $\mathrm{H}$ instead of a full coverage, and so, such a $(1 \times 2)$ arrangement is thermodynamically clearly preferred.

The 1 ML situation is still exothermic, and so, a $(1 \times 1)$ periodicity is actually feasible. Indeed, previous experiments combining LEED and He-Atom Scattering $(H A S)$ experiments detected such a $(1 \times 1)$ arrangement. ${ }^{67}$ In this latter study the activation energy for $\mathrm{H}_{2}$ - 
desorption was found to be $141 \mathrm{~kJ} \mathrm{~mol}^{-1}$, in perfect line with the present estimate for the desorption energy of $152 \mathrm{~kJ} \mathrm{~mol}^{-1}$ at $\theta=1 \mathrm{ML}$, corroborating the possible existence of a $(1 \times 1)$ arrangement. This is also back-supported by previous XPS simulations and calculations showing that core level $\mathrm{O} 1 \mathrm{~s}$ signals assigned to surface hydroxyl groups can only be explained when having full hydrogen coverage. ${ }^{67,90}$

When addressing the arrangement issue from the point of view of IR techniques one encounters a few discrepancies in the literature. Previous IR studies on the $\mathrm{H}(1 \times 1)$ $\mathrm{ZnO}(000 \overline{1})$ pattern formed after exposing the $\mathrm{ZnO}$ single crystal surface to water vapor at room temperature found a peak at $3572 \mathrm{~cm}^{-1}$, assigned to the hydroxyl stretching vibration, ${ }^{91}$ whereas a more recent HREELS study assigned a peak at $3621 \mathrm{~cm}^{-1}$ to the aforementioned hydroxyl vibration after exposing 2 Langmuir $(L)$ of $\mathrm{H}_{2} \mathrm{O}$ to the single crystal surface, also at room temperature. ${ }^{44}$ Indeed, a simpler explanation for this discrepancy is that values were obtained at moderate ${ }^{91}$ and low ${ }^{44}$ water partial pressure. Previous theoretical studies show that in H-rich conditions (high pressure) and high temperature (800 K) coverage above $0.5 \mathrm{ML}$ and even the full coverage situation approach in stability to the $(1 \times 2)$ arrangement. ${ }^{52}$ However at such elevated temperature values surface $\mathrm{H}$ is known to recombine and desorb as $\mathrm{H}_{2}$, as found already to happen at $547 \mathrm{~K}$ for a $(1 \times 1)$ situation. ${ }^{67}$ Nevertheless the full coverage phase at H-rich conditions could be plausible at lower room temperature.

Present IR simulations on Figure 2 show that at 1 ML coverage only the $\mathrm{OH}$ symmetric stretching vibration is active, centered at $3486 \mathrm{~cm}^{-1}$, sensibly below the peak found when exposing the single crystal surface to water. An important point here is that there is a very large difference between this IR fingerprint and that of coverage 0.5 ML. When decreasing the coverage to the $(1 \times 2)$ pattern, the hydroxyl structure is only very weakly modified, with $\mathrm{OH}$ bond length decreased by only $2 \mathrm{pm}$, and the hydroxyls slightly less normal to surface. However, the bonding energy is increased by more than $100 \mathrm{~kJ} \mathrm{~mol}^{-1}$, which has a critical impact on the hydroxyl stretching frequency, which blue-shifts more than 
$250 \mathrm{~cm}^{-1}$ to reach a value of $3744 \mathrm{~cm}^{-1}$. This last stretching frequency should be assigned to the $3621 \mathrm{~cm}^{-1}$ peak observed at low pressures, ${ }^{44}$ where the formation of a $(1 \times 2)$ pattern seems to be clear. The additional experimental peak ${ }^{91}$ at $3572 \mathrm{~cm}^{-1}$ appears at a somewhat larger value than the one calculated at saturation coverage, and so probably belongs to an intermediate situation, e.g. $2 / 3$ or $3 / 4 \mathrm{ML}$, as previously found to be also energetically competitive situations. ${ }^{52}$

(0001) surface: Previous HAS studies showed that when this surface is exposed to hydrogen, a weakly bound $(1 \times 1)$ hydride pattern is formed. Reports combining Scanning Tunneling Microscopy (STM) images and DF calculations showed that such a single crystal surface displays triangular pits, ${ }^{51,53}$ and recent theoretical surface phase diagrams assign the $(1 \times 1)$ pattern to a situation with full hydride coverage on triangular pits and islands. ${ }^{92}$ Current computed adsorption sites and energies are in perfect agreement with those of Kresse and coworkers, ${ }^{53}$ showing an essentially isothermic adsorption at $\theta=0.5 \mathrm{ML}$ and a disfavored adsorption process at $1 \mathrm{ML}$, also in line with a previous experimental report showing a $\mathrm{H}_{2}$ desorption energy of a few $\mathrm{kJ} \mathrm{mol}^{-1}$. Probably the instability at full coverage is at the origin of the observed reconstruction and formation of a rough surface. ${ }^{93}$ In any case, the predicted arrangements are similar to those of $(000 \overline{1})$ surface, but with a sensibly larger $\mathrm{ZnH}$ bond length of 155-160 pm, in very good agreement with recent DF calculations at Local Density Approximation $(L D A)$ level. ${ }^{94}$ The IR simulated spectra signals are attenuated by $\sim 30$ times compared to the $\mathrm{OH}$ stretching vibrations found on $(000 \overline{1})$ surface, here the peaks situated around 1833 and $1499 \mathrm{~cm}^{-1}$ at half and full coverage, respectively, allowing also for a clear distinction of the degree of coverage based on IR measurements,.

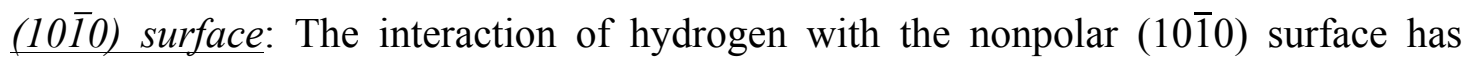
driven lately very much attention due to the so-called surface metallization effect appearing when exposing this surface to hydrogen at room temperature. ${ }^{45,95-97}$ This is found to happen when all surface oxygen atoms are bonded to a $\mathrm{H}$ adatom. HREELS experiments detected a 
peak at $\sim 3645 \mathrm{~cm}^{-1},{ }^{45}$ which could belong to presently simulated IR at $3586 \mathrm{~cm}^{-1}$. At low temperatures (below $200 \mathrm{~K}$ ), another vibrational signature is observed at $1613 \mathrm{~cm}^{-1}$, assigned to a $\mathrm{Zn}-\mathrm{H}$ hydride stretching. This would correspond to a full saturation coverage in which both surface $\mathrm{Zn}$ and $\mathrm{O}$ atoms are attaching hydrogen species, i.e. simultaneously forming hydride and hydroxyl species. This arrangement has been observed by atomic-resolved $\mathrm{STM}^{95}$ and it has also been found not to induce a metallization of the (1010) surface. ${ }^{45,98}$

According to present calculations, the adsorption of $\mathrm{H}$ to form surface hydroxyls would be, similarly to (0001) surface, an isoenergetic process when taking $\mathrm{H}_{2}$ in vacuum as the energy reference. The formation of sole $\mathrm{ZnH}$ hydride species was found to be thermodynamically prohibitive. Concerning the IR simulated spectra in Figure 2, the surface hydroxyl stretching is active and observable, although the intensity is clearly inferior to those spectra of $(000 \overline{1})$ polar surface. The attenuation of the signal is more acute in the $\theta=0.5 \mathrm{ML}$ case, due in principle to the tightening of the $\mathrm{O}_{\mathrm{s}}-\mathrm{H}$ bond, as found also for the polar surfaces.

We also studied the $(1 \times 1)(10 \overline{1} 0)$ unit cell containing hydride and hydroxyl moieties. During the geometry optimization the system undergoes a peculiar relaxation, which involves an inversion of the $\mathrm{ZnO}$ angle $-7.1^{\circ}$ with respect the surface plane, see Supplementary Information - having $\mathrm{Zn}$ as the most exposed surface atom, similarly to earlier results obtained at B3LYP hybrid functional level. ${ }^{98}$ We found an elongation of $29.5 \mathrm{pm}$ of the surface $\mathrm{ZnO}$ bond length, and a small contraction of $\mathrm{ZnH}$ bond of $2 \mathrm{pm}$ (Table 1). The adsorption energy accounting for $\mathrm{H}_{2}$ gas dissociation results in an exothermic process of $43 \mathrm{~kJ}$ $\mathrm{mol}^{-1}$, at variance with previous theoretical studies using pair-potentials, which erroneously found such dissociated system to be endothermic by around $500 \mathrm{~kJ} \mathrm{~mol}^{-1}$, a feature arising from the limitations of such empirical approach. ${ }^{99}$ When having both species, the overall adsorption strength is enhanced, due to the bulk near-tetrahedral coordination geometry recovery. ${ }^{100}$ The simulated IR spectra shown in Figure 3 displays two peaks at 1797 and 3601 $\mathrm{cm}^{-1}$ belonging to surface $\mathrm{Zn}-\mathrm{H}$ or $\mathrm{O}_{\mathrm{s}}-\mathrm{H}$ stretching vibrations, respectively. These would 
correspond to the observed peaks by Wang et al. at 1613 and $3670 \mathrm{~cm}^{-1}$, respectively. ${ }^{45}$ An ONIOM study lead to vibrational modes located at $1460 \mathrm{~cm}^{-1}$ and $3516 \mathrm{~cm}^{-1},{ }^{100}$ a clear improvement compared to other embedded cluster studies where stretching modes were located at 1540 and $4018 \mathrm{~cm}^{-1} .{ }^{99}$ Interestingly, according to current results the desorption of Zn hydride species would suppose a red shift of $15 \mathrm{~cm}^{-1}$ in hydroxyl signal, never mentioned in the HREELS experiments, although a close inspection to the spectra seems to support it. ${ }^{45}$

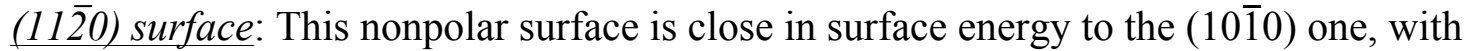
past and present estimates of the surface energy showing a difference of only $\sim 0.1 \mathrm{~J} \mathrm{~m}^{-2}, 99,101$ and frequently detected in XRD experiments. ${ }^{11,23,25,29,32}$ The interest in the interaction of $\mathrm{H}_{2}$ with this particular surface is clearly detrimental with respect the others with no previous experimental nor DF reports on the interaction of atomic or molecular hydrogen with this surface. Present results show a situation somewhat similar to that above described for the (1010) surface. One similarity is the clear preference to form hydroxyls: Note that the computed $E_{a d s}$ to form a $\mathrm{Zn}-\mathrm{H}$ species at $\theta=0.5 \mathrm{ML}$ is presently computed to be $156 \mathrm{~kJ} \mathrm{~mol}^{-1}$, $48 \mathrm{~kJ} \mathrm{~mol}^{-1}$ less stable than the hydroxyl value listed in Table 1 . Note besides that the hydroxyl bond lengths are almost equal to those on the parent (1010) nonpolar surface, also displaying a reduction in the bond strength and orthogonality to the surface plane when reaching $1 \mathrm{ML}$ (Table 1). The IR simulated spectra shown in Figure 2 reveal that stretching frequencies are red-shifted with respect those of (1010) surface reflecting a slightly weaker bond strength. The result is somehow surprising since a stronger bond would be expected given the lower stability of this surface, or, in other words, a higher surface activity. This hindered surface activity results in adsorption energies that suggest an endothermic $\mathrm{H}_{2}$ dissociative adsorption process, by $\sim 44 \mathrm{~kJ} \mathrm{~mol}^{-1}$, exclusively forming hydroxyl moieties.

Analogously to $(10 \overline{1} 0)$ surface we computed a $(1 \times 1)$ unit cell model of the (11200) surface fully covered with $\mathrm{H}$, containing both hydride and hydroxyl species. The 
structure evolves in a similar fashion as found for the (1010) surface, with $\mathrm{Zn}-\mathrm{H}$ and $\mathrm{O}_{\mathrm{s}}-\mathrm{H}$ bond lengths remaining similar, although an elongation by $23.3 \mathrm{pm}$ is found for the surface $\mathrm{ZnO}$ bond, accompanied with an inversion of the angle with respect the surface plane, now having an angle of $6.8^{\circ}$ but exposing surface $\mathrm{Zn}$ atoms (Table 1 and Supplementary Information). The process is estimated to be exothermic by $47 \mathrm{~kJ} \mathrm{~mol}^{-1}$. Figure 3 contains the corresponding vibrational fingerprint, showing active stretching frequencies located at 1814 and $3606 \mathrm{~cm}^{-1}$. As happened on $(10 \overline{1} 0)$ surface the full coverage of the $(11 \overline{2} 0)$ surface with $\mathrm{Zn}-\mathrm{H}$ and $\mathrm{O}_{\mathrm{s}}-\mathrm{H}$ entities leads to a situation with enhanced stability, due mostly to the bulk coordination recovery.

Surfaces and Nanoparticles: Now light is shed in experimental samples containing simultaneously two or more of the above discussed surfaces. One particular case would be for instance, systems exhibiting both basal polar planes. Concurrent exposition of (0001) and $(000 \overline{1})$ surfaces to hydrogen leads to additive situations: Already at low or high-vacuum pressure conditions, the O-terminated $(000 \overline{1})$ surfaces will firstly display a $(1 \times 2)$ hydroxyl pattern, explaining the observed sharp signal at $\sim 3620 \mathrm{~cm}^{-1} \cdot 34,44$ By increasing the exposure/pressure, a nearly or fully hydrogen covered (0001) surface is feasible, and so the half coverage of (0001) surface. This situation would exhibit hydroxyl and hydride peaks located at 3489 and $1833 \mathrm{~cm}^{-1}$, which allows one to assign the observed signals at 3450-3500 $\mathrm{cm}^{-1}$ and $\sim 1710 \mathrm{~cm}^{-1}$ in the experiments exposing $\mathrm{H}_{2}$ at moderate or large pressures to $\mathrm{ZnO}$ nanoparticles faceting such polar surfaces. ${ }^{34,48-50}$ Previous Quantum Mechanics/Molecular Mechanics $(Q M / M M)$ calculations needed to invoke surface vacancies to explain the experimentally observed signals. ${ }^{102,103}$

Note that when studying $\mathrm{ZnO}$ nanoparticles one has to consider the ratio between polar/nonpolar surfaces. Previous HRTEM and FTIR experiments have shown that, typically, on $\mathrm{ZnO}$ nanopowder particles, $80 \%$ of the surface corresponds to nonpolar faces. ${ }^{95,104}$ In this sense, the relatively low IR intensity of nonpolar hydrogenated surfaces is partially 
counterbalanced by their highest exposure, and so, in principle observable. This is in perfect agreement with the FTIR signal at $3672 \mathrm{~cm}^{-1}$ observed when exposing $\mathrm{ZnO}$ nanoparticles to atomic hydrogen in UHV conditions. ${ }^{34}$ In these experiments, the rapid appearance of a dominant peak at $3618 \mathrm{~cm}^{-1}$ corresponds to the strong hydrogen adsorption on the $(000 \overline{1})$ facets forming a $(1 \times 2)$ pattern of hydroxyls, and only after more exposure the nonpolar surfaces are hydrogenated, although $(10 \overline{1} 0)$ and $(11 \overline{2} 0)$ become indistinguishable. According to present results displayed in Figure 3, a distinction of both surfaces could only be reached by scanning the $1650-1850 \mathrm{~cm}^{-1}$ region with a high-resolution IR technique.

\subsection{OH Adsorption}

Here we have investigated the adsorption of $\mathrm{OH}$ on the different würtzite $\mathrm{ZnO}$ surfaces. Case studies concerning $\mathrm{H}_{2} \mathrm{O}$ and co-presence of $\mathrm{H} / \mathrm{OH}$ moieties are presented in the next section, since considering separately both complementary $\mathrm{H}$ and $\mathrm{OH}$ studies permits one to elucidate the stability and arrangement of water scission moieties. Structural, energetic, and vibrational data for the most stable adsorption cases of $\mathrm{OH}$ on each surface are provided in Table 2.

(0001) surface: Here only one stable site is found, having the hydroxyl adsorbed on a 3-fold hollow site - connecting three surface $\mathrm{Zn}$ species and therefore, a $\mu^{3}$ adsorption mode - with no $\mathrm{ZnO}$ oxygen directly beneath, see Figure 4 . The $\mu^{3}$ mode with an underneath oxygen is destabilized by more than $50 \mathrm{~kJ} \mathrm{~mol}^{-1}$, and therefore has not been further considered. In the $\mu^{3}$ conformation the adsorption strength is rather high, almost $400 \mathrm{~kJ} \mathrm{~mol}^{-1}$ at $\theta=0.5 \mathrm{ML}$, and the hydroxyl stays essentially perpendicular to the (0001) surface. By reaching full coverage the lateral repulsion reduces the adsorption energy by $\sim 120 \mathrm{~kJ} \mathrm{~mol}^{-1}$, with very small structural changes and only a small increase of the molecular perpendicularity towards the surface. The vibrational frequency at half coverage of $3755 \mathrm{~cm}^{-1}$, gets red shifted by $\sim 11 \mathrm{~cm}^{-1}$ when reaching a full coverage, providing a noticeable IR signal as seen in Figure 
4. It is worth to mention that in the earlier study of Wander and Harrison on water adsorption on a $\mathrm{ZnO}(0001) /(000 \overline{1}) \mathrm{slab}^{72}$ the hydroxyls were put directly on top of surface $\mathrm{Zn}$ atoms in the (0001) surface, although according to present results such mode is found to be unstable. Actually, it could well be that in the work of Wander and Harrison the $\mathrm{OH}$ was kept on-top during optimization simply for symmetry reasons, and thus, its higher energy would explain their finding of hydroxylated $\mathrm{ZnO}(0001) /(000 \overline{1})$ slab being less stable than the pristine one, ${ }^{72}$ contrary to the experimental observation of high reactivity of polar surfaces on water splitting, and the easiness of getting them hydroxylated, with water splitting activation barriers being, if any, very small. ${ }^{105}$

$(000 \overline{1})$ surface: Here the hydroxyls are less stable than on the (0001) surface, and actually, only a minimum energy structure at $\theta=0.5 \mathrm{ML}$ is found, which corresponds to a $\eta^{2}$ conformation in which $\mathrm{OH}$ lies almost planar to the surface, with the $\mathrm{O}$ atom connected to a surface $\mathrm{O}$ atom, and the $\mathrm{H}$ atom pointing to a hollow site, maybe forming a $\mathrm{H}-$ bond, given the distance of $248 \mathrm{pm}$ to neighboring $\mathrm{OH}$ group. The moiety planarity makes this particular sorption mode almost undetectable by IR techniques, as seen in Figure 4, with vibrations $\sim 4$ times attenuated with respect hydroxyl signals on (0001) surface. At full coverage, the isolated adsorption of $\mathrm{OH}$ moieties is highly unstable, and actually spontaneous hydroxyl disproportionation into water and $\mathrm{O}$ adatoms is observed, as seen in sketches of Figure 4. The water molecules lay rather planar to the $(000 \overline{1})$ surface, and so the vibrational fingerprint intensities are comparable to those of half coverage situation. Symmetric and asymmetric water stretching modes are located at 3506 and $3683 \mathrm{~cm}^{-1}$, respectively. Note in passing that bending mode is detected as well at $1573 \mathrm{~cm}^{-1}$. Overall, IR signals of hydroxyl moieties on the polar $(000 \overline{1})$ surface are rather weak and, if existing, would be shadowed by $\mathrm{OH}$ species on other surfaces, see below. 


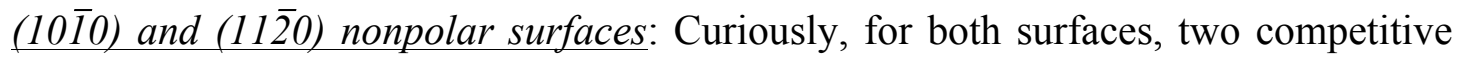
adsorption minima are found. For the (1010) surface these are named $\mu^{1}$ and $\mu^{2}$ conformations. In the latter, the $\mathrm{OH}$ Oxygen atom attaches bridging two adjacent $\mathrm{Zn}$ atoms, with its $\mathrm{H}$ atom pointing towards the vacuum, see Figure 4. This particular coordination mode has been recently found to be a metastable fragment in water dissociation, according to B3LYP and PBE DF calculations. ${ }^{61,106}$ At full coverage it has a characteristic $\mathrm{OH}$ stretching at $3736 \mathrm{~cm}^{-1}$. By decreasing the coverage to $0.5 \mathrm{ML}$, there is only a slight increase of surface bond strength, although accompanied by a red shift of $\sim 15 \mathrm{~cm}^{-1}$, and a slight decrease of the hydroxyl perpendicularity which, however, does not perturb the IR intensity, see Figure 4. In the $\mu^{1}$ mode the hydroxyl is attached to a surface $\mathrm{Zn}$ atom, with the $\mathrm{H}$ atom pointing towards the neighboring hydroxyl species, maybe forming a H-bond, with a separation of $246 \mathrm{pm}$, in a similar fashion to the $(000 \overline{1})$ case. The $\mu^{1}$ mode is only slightly higher in energy, by $\sim 4-6 \mathrm{~kJ}$ mol $^{-1}$, with respect $\mu^{2}$ mode - here both considered isoenergetic — and displays the hydroxyls rather parallel to the surface, with an angle of $0.7^{\circ}$ at $\theta=0.5 \mathrm{ML}$. This makes the $\mu^{1}$ mode undetectable by IR signal. At $1 \mathrm{ML}$ coverage, hydroxyls are essentially parallel to the $(10 \overline{1} 0)$ surface, and their stretching vibrations, estimated to be centered at $\sim 3631 \mathrm{~cm}^{-1}$, could be

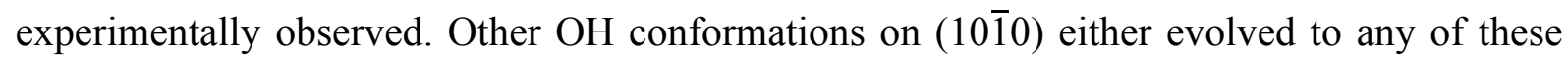
two situations, or where higher in energy by at least $20 \mathrm{~kJ} \mathrm{~mol}^{-1}$.

On the $(11 \overline{2} 0)$ surface the most stable adsorption conformation, hereafter referred to $\eta^{2}$, corresponds to a situation where the hydroxyl moiety is attached to a surface $\mathrm{Zn}$ atom, although with the $\mathrm{H}$ atom oriented towards a surface $\mathrm{O}$ atom of a vicinal zig-zag stripe, see Figure 4. Here the H-bond is more evident, with an interatomic distance of $212 \mathrm{pm}$ at $\theta=0.5$ ML. However, as happened with the $\mu^{1}$ mode on the (1010) surface, the high planarity makes the $\eta^{2}$ mode stretching IR-inactive. Curiously, at $\theta=1 \mathrm{ML}$, the adsorption strength slightly increases by $11 \mathrm{~kJ} \mathrm{~mol}^{-1}$, revealing an adsorption synergy directed by $\mathrm{H}$-bonds formation, 
given the shorter distances $191 \mathrm{pm}$ in between surface hydroxyls. As seen in Figure 4, hydroxyls align themselves along the $(11 \overline{2} 0)$ surface grooves, staying also highly planar to surface. Therefore, its IR peak located at $3366 \mathrm{~cm}^{-1}$ displays low intensity, and would be observed as a broad peak in experiments. As seen below, this particular arrangement is a clear precursor of the fully hydrated $(11 \overline{2} 0)$ surface. The other mode, named $\eta^{1}$, simply corresponds to a hydroxyl adsorption on a surface $\mathrm{Zn}$ atom, with $\mathrm{H}$ pointing towards the vacuum. This conformation is only $2 \mathrm{~kJ} \mathrm{~mol}^{-1}$ less stable and so considered isoenergetic to the $\eta^{2}$ mode. This mode is IR-active, with a stretching frequency at $3733 \mathrm{~cm}^{-1}$ at half coverage. At full coverage, the hydroxyls align, maybe making H-bonds (267 pm), with a characteristic peak situated at $3660 \mathrm{~cm}^{-1}$.

\subsection{Full Analysis of $\mathrm{H} / \mathrm{OH} / \mathrm{H}_{2} \mathrm{O}$ Species on Polar and Nonpolar Surfaces}

The information of the preferential adsorption of $-\mathrm{OH}$ and $-\mathrm{H}$ moieties has been used to sample different arrangements of split water molecules on the different surfaces. Let us consider first of all $\mathrm{ZnO}$ slabs simultaneously exhibiting (0001) and (000) surfaces. According to Tables 1 and 2, hydroxyl attachment is highly preferred over hydrogen on the

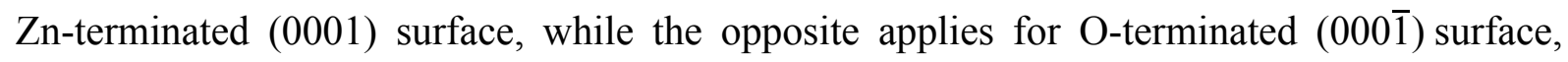
following the situation posed by Wander and Harrison. ${ }^{72}$ Accounting for this and also considering that, according to present calculations, the scission of a $\mathrm{H}_{2} \mathrm{O}$ molecule into $\mathrm{OH}$ and $\mathrm{H}$ in vacuum has an energy cost of $519 \mathrm{~kJ} \mathrm{~mol}^{-1}$, one may discuss the possibility of simultaneously adsorbing $\mathrm{H}$ and $\mathrm{OH}$ on their respective surfaces at different coverage. Filling half the (0001) surface with hydroxyls and half of the $(000 \overline{1})$ surface with hydrogen atoms leads to a final value of released energy of $286 \mathrm{~kJ} \mathrm{~mol}^{-1}$ per surface supercell unit.

This tremendous exothermicity explains the easiness of detecting hydroxyls on both surfaces. ${ }^{105}$ At $\theta=1 \mathrm{ML}$ the degree of exothermicity largely reduces to $96 \mathrm{~kJ} \mathrm{~mol}^{-1}$, revealing, in a similar fashion to $\mathrm{H}_{2}$ adsorption discussed in the previous point, that a $(1 \times 2)$ pattern is 
thermodynamically clearly preferred. The full coverage is not thermodynamically hindered though, and could be achievable by increasing the $\mathrm{H}_{2} \mathrm{O}$ vapor pressure, although the stability difference of almost $200 \mathrm{~kJ} \mathrm{~mol}^{-1}$ makes it rather costly. The vibrational fingerprint at $\theta=0.5$ ML is shown in Figure 5 for both polar surfaces. The small difference of $11 \mathrm{~cm}^{-1}$ between frequencies of hydroxyls of different polar surfaces (Tables 1 and 2) makes their identification rather cumbersome, accentuated by their high difference in IR intensity. Indeed, signals on the $(000 \overline{1})$ face are a priori a hundred times more intense, and likely to be the ones to be observed, being the $\mathrm{OH}$ stretching from (0001) surface hidden in the peak tail.

On the (1010) surface, a previous study by Meyer et al. showed by combining PBE slab calculations and STM images, the existence of a partially dissociated water $(2 \times 1)$ monolayer after exposing the single crystal surface to $1 \mathrm{~L}$ of $\mathrm{H}_{2} \mathrm{O} .{ }^{16}$ The stability of this peculiar arrangement was compared to the non-dissociated water monolayer, and also to the completely dissociated case. ${ }^{16,54,61}$ Notice that $\mathrm{H}_{2} \mathrm{O}$ molecules can be adsorbed on the $\mathrm{ZnO}$ dimer stripes, above the surface grooves, or alternatively sampling stripe and groove positions. In addition, the distinction between stripe and groove positions affects the number of possibilities for the mixed dissociated case. Furthermore, as shown in Table 2, the hydroxyl moieties can display $\mu^{1}$ and $\mu^{2}$ conformations. All possible moiety combinations meeting the $(2 \times 1)$ surface pattern have been optimized, the most stable one being precisely that previously proposed. ${ }^{16,54,61}$ Within this arrangement every second $\mathrm{H}_{2} \mathrm{O}$ molecule is adsorbed over the surface groove, and the other half becomes dissociated into hydroxyl and hydrogen atoms, see Figure 5, in line with a very small dissociation energy barrier of 5-8 $\mathrm{kJ} \mathrm{mol}^{-1} .^{61,106}$ The rest of adsorption conformations lay $20 \mathrm{~kJ} \mathrm{~mol}^{-1}$ or higher in energy. As happened when dissociating $\mathrm{H}_{2}$, the surface atoms recover a near-tetrahedral geometry, ${ }^{100}$ in which $\mathrm{ZnO}$ surface units elongate their bonds by $18.7 \mathrm{pm}$, and surface rumpling essentially vanishes. 
The same procedure was carried out for the $(11 \overline{2} 0)$, accounting for both $\eta^{1}$ and $\eta^{2}$ adsorption modes. Here, in accordance to previous simulations at LDA level, ${ }^{54}$ the completely dissociated arrangement is clearly preferred over mixed situations by $\sim 15 \mathrm{~kJ} \mathrm{~mol}^{-1}$. This particular arrangement resembles the $\eta^{2}$ conformation at $\theta=1 \mathrm{ML}$, but with hydroxyls involving surface $\mathrm{O}$ atoms, $\mathrm{O}_{\mathrm{s}}$, see Figure 5. Here, an elongation of surface $\mathrm{Zn}-\mathrm{O}$ bond lengths of $14.8 \mathrm{pm}$ is found and also, an inversion of the surface angle $\left(7.6^{\circ}\right)$ now exposing more the surface $\mathrm{Zn}$ atoms. Structural, energetic, and vibrational data of the partially dissociated $(2 \times 1)$ pattern of $\mathrm{H}_{2} \mathrm{O}$ on $(10 \overline{1} 0)$ and of the completely dissociated $(1 \times 1)$ pattern on $(11 \overline{2} 0)$ surface are gathered in Table 3, and their vibrational fingerprints are shown in Figure 5. On both nonpolar surfaces a distinction is made for hydroxyls arising from water splitting $(-\mathrm{OH})$, and those formed by the adsorption of a $\mathrm{H}$ adatom on a surface Oxygen atom $\left(\mathrm{O}_{\mathrm{s}}-\mathrm{H}\right)$.

Considering the (1010) surface, the simulated IR spectra are governed by two peaks, located at 3155 and $3765 \mathrm{~cm}^{-1}$. The experimental HREELS by Wang et al. showed that after exposing the (1010) surface to water, two main features were detected; a broad band at 3195 $\mathrm{cm}^{-1}$, assigned, in principle, to a water $-\mathrm{OH}$ implied in a $\mathrm{H}-$ bond, and another at $3670 \mathrm{~cm}^{-1}$ assigned to a partially dissociated $\mathrm{H}_{2} \mathrm{O}$ molecule. ${ }^{46}$ However, in light of the present results, this assumption is proven to be only half true. Whereas the peak at $3670 \mathrm{~cm}^{-1}$ would actually belong to an O-H stretching from a partially dissociated water molecule - the underestimation of $\sim 100 \mathrm{~cm}^{-1}$ in our calculations is mainly due to the lack of description of anharmonicity, as shown below - the peak at $3195 \mathrm{~cm}^{-1}$ is, according to present model calculations, due to $\mathrm{O}_{\mathrm{s}}-\mathrm{H}$ hydroxyl stretching. In the HREELS experiments a shoulder of the $3670 \mathrm{~cm}^{-1}$ signal — specified as a peak located at $3700 \mathrm{~cm}^{-1}$ - was assigned to a non-Hbonded $\mathrm{OH}$ from the intact water molecules. However, as observed in Figure 5, these modes are actually located below $3000 \mathrm{~cm}^{-1}$. 
Note that water molecule lays rather planar to the surface, and consequently its IRactive vibration modes are rather weak in intensity. Indeed, its stretching modes are found to be slightly coupled with the $\mathrm{O}_{\mathrm{s}}-\mathrm{H}$ mode, and it is because of this that they have an appreciable intensity. All these modes are responsible of the broad band centered at $3195 \mathrm{~cm}^{-1}$ as found by Wang et al., ${ }^{46}$ which indeed could be composed of many superimposed contributions. Last but not least, according to present calculations, there is no explanation for the peak at $3700 \mathrm{~cm}^{-1}$, suggesting that such a peak might be apparent, and in reality not belonging to any particular vibrational mode. This statement is supported by FTIR UHV experiments of Noei and coworkers $^{47}$ on $\mathrm{ZnO}$ nanoparticles, who did not detect such a signal, despite (1010) surface, due to its stability, is the dominant surface on many $\mathrm{ZnO}$ nanoparticles. Although not shown on Figure 5 , the $(10 \overline{1} 0)$ surface displays a water scissor mode calculate to be at $1651 \mathrm{~cm}^{-1}$ displaying a low intensity, in accordance to FTIR experiments by Noei et al who detected such mode at $1617 \mathrm{~cm}^{-1} .{ }^{47}$

As far as the $(11 \overline{2} 0)$ nonpolar surface is considered, there is, regretfully, no IR experiments - to the best of our knowledge - carried out on single crystal surfaces. However, present estimates point for a clear identification of such a surface, with its IR signals at $\sim 2590$ and $\sim 3400 \mathrm{~cm}^{-1}$, being the $\mathrm{O}_{\mathrm{s}}-\mathrm{H}$ and $\mathrm{OH}$ moieties, respectively. Note that both kind of hydroxyls are involved in H-bonding, and so, the experimental peaks may display certain broadness. Despite the lack of experimental input, the (1120) signals can be detected in $\mathrm{ZnO}$ nanoparticles mainly exposing nonpolar surfaces, given the similar stability to (1010) surface. DRIFTS and FTIR spectra by Noei et al. showed that when exposing ZnO nanoparticles to $\mathrm{H}_{2} \mathrm{O}$, two peaks at $\sim 3620$ and $\sim 3670 \mathrm{~cm}^{-1}$ appeared, belonging to $(10 \overline{1} 0)$ and $(000 \overline{1})$ hydroxyl stretching modes, ${ }^{47}$ in accordance to simulated IR shown in Figure 5 - the experimental peak difference of $50 \mathrm{~cm}^{-1}$ is somewhat underestimated by $30 \mathrm{~cm}^{-1}$ according to present calculations. Curiously, UHV-FTIR experiments revealed an emerging peak at $\sim 3440$ 
$\mathrm{cm}^{-1}$, which, according to present calculations, would well belong to the $\mathrm{OH}$ stretching modes on the nonpolar $(11 \overline{2} 0)$ surface. The exact assignment of the contribution located around $3400-3450 \mathrm{~cm}^{-1}$ is however complex, and is further analyzed in the following section.

\subsection{Surface Species at ZnO Nanoparticles Interacting with $\mathrm{H}_{2} \mathrm{O}$}

To analyse the significance of our IR study for water-related species at $\mathrm{ZnO}$ nanostructures, we synthesized two materials: One dominated by nonpolar facets (sample A) and another by polar facets (sample B). In the first case, sample A, HR-TEM image and the corresponding FFT diffraction pattern (Figure 6) indicate the presence of well-defined elongated nanostructures along the $c$ crystallographic orientation displaying a $[01 \overline{1} 0]$ zone axis. This brick-like structure is representative of sample surfaces dominated by nonpolar surfaces. Figure 6 also presents HR-TEM images for sample $\mathbf{B}$ and the corresponding FFT diffraction pattern of the selected zone of the needle entities. The analysis unequivocally identifies a [0001] zone axis. Therefore the nanostructure grows in a direction perpendicular to the crystallographic $c$ axis mainly exposing polar $(0001) /(000 \overline{1})$ facets along the needle particulate surface layer.

The experimental DRIFTS data of the samples and corresponding hydroxyl-related contributions are presented in Figure 7. Two different spectra are presented for samples $\mathbf{A}$ and B, obtained after dehydration treatments at 150 and $350{ }^{\circ} \mathrm{C}$. For any of the shown cases the spectra can be divided in three different regions defined by cut off levels at circa 3100 and $3370 \mathrm{~cm}^{-1}$. The first region contains relatively small contributions which are presumably dominated by interacting $\mathrm{OH}$ species as well as molecularly adsorbed water contributions. ${ }^{107}$ The next two regions contain contributions for isolated $\mathrm{OH}$ species ${ }^{47-50,107}$ and have variable importance in the two samples. Such issue becomes visually evident by the different colourcode used in Figure 7 for the analysed $\mathrm{ZnO}$ surfaces. The fitting here illustrated using 8 contributions is suggested by the derivative of the spectra (shoulders during the slow decay 
are particularly evident in sample B) as well as theoretical predictions previously discussed. Furthermore, larger differences between the IR spectra of both samples are noteworthy for the higher dehydration temperature, as the masking contribution from adsorbed water is significantly decreased, highlighting alongside the predominance of the peak at $\sim 3400 \mathrm{~cm}^{-1}$ on sample B. Last but not least, the higher dehydration temperature unveils a peak located at $\sim 3670 \mathrm{~cm}^{-1}$, which could belong to either $(10 \overline{1} 0)$ or $(000 \overline{1})$ hydroxyl stretching modes, in accordance to previous DRIFTS and FTIR experiments. ${ }^{47}$ Note that bands in Figure 7 for different samples/treatments are not exactly at the same frequency due to morphology/coverage differences influencing the coupling between vibrational modes of individual molecules within a layer of adsorbates (i.e. H bonding). Details of this issue for $\mathrm{ZnO}$ extended surfaces and nanoparticles can be found in refs. 34, 47, 107. The Supporting Information gives details about the statistical significance of using 8 contributions, as well as additional physical insights. More importantly, rather than the existence and/or definitive assignment of each band presents in an experimental spectrum, the dominance of polar or nonpolar surfaces at one specific frequency region (above or below the two cut-off points mentioned) would be the key factor in interpreting the IR-derived morphology information at nanoparticles.

The detailed interpretation of the IR active species experimentally detected is therefore presented in Figure 8. Such interpretation comes from analysing the relative contribution of the IR bands observed in Figure 7 and confronting such result with the theoretical expectation derived from Figure 5. Note that this latter figure displays the intensity as well as the frequency of the corresponding surface moieties, allowing a meaningful description of the vibrational features arising from surface species. Most important differences between our theoretical and experimental results would be related to a frequency shift between them; experimental results presenting always lower frequency values than theoretical ones, as expected due to anharmonic contributions not considered in the calculations and to an 
inevitable inaccuracy of DF calculations too. In particular, the computed water harmonic symmetric and asymmetric stretching vibrations (3867 and $3753 \mathrm{~cm}^{-1}$, respectively) are $\sim 100$ $\mathrm{cm}^{-1}$ overestimated compared to anharmonic experimental values $\left(3756\right.$ and $\left.3657 \mathrm{~cm}^{-1}\right) .{ }^{108}$

Although real samples have contributions from many different surface planes, the study of the four model surfaces in the previous sections is able to provide a nearly complete description of the IR spectrum at the hydroxyl region. Starting from the low wavenumber region, below $3100 \mathrm{~cm}^{-1}$, of Figures 7 and 8 , the study mostly indicates the dominant presence of water species present at the $(10 \overline{1} 0)$ nonpolar surface. Of course, we cannot discard the presence of physisorbed water species at several surfaces which would be hardy distinguishable among them due to the fact the frequency would be dominated by adsorbateadsorbate interactions rather than adsorbate-surface interactions. Furthermore, this would be the region where a broad band belonging to $\mathrm{O}_{\mathrm{s}}-\mathrm{H}$ stretching vibrations of $(11 \overline{2} 0)$ surface would be detected. Still the above-mentioned theoretical results indicate the stability of $\mathrm{H}_{2} \mathrm{O}$ absorbed species at the (1010) nonpolar surface and thus the predominance in our experimental conditions where desorption of physisorbed water molecules is favoured. The assignment of the zones above $3100 \mathrm{~cm}^{-1}$ provides however conclusive evidence of the presence of specific surface planes in the $\mathrm{ZnO}$ nanoparticle samples. First it can be seen in Figure 8 that this is a zone dominated by surface contributions of nonpolar surfaces (e.g. bands between 3100 and $3370 \mathrm{~cm}^{-1}$ ). In agreement with this, we can see that the brick-type $\mathbf{A}$ sample presents a significantly larger intensity contribution than needle-type B sample.

The zone around $3370-3450 \mathrm{~cm}^{-1}$ displays an important single contribution. As it presents more significant intensity in sample $\mathbf{B}$ - mainly exposing polar $(0001) /(000 \overline{1})$ facets - than sample $\mathbf{A}$ it could be expected to be related to polar surfaces. We may suggest that it would correspond to $\mathrm{O}_{\mathrm{s}}-\mathrm{H}$ species on $(000 \overline{1})$ polar surfaces. This correlates well with the features presented in Figure 2 and Table 1 considering that the exact peak position for such adspecies depends critically on coverage (as it was discussed above, contributions 
located between the two frequencies presented in Figure 2 are possible in experimental studies in dependence on the exact coverage of the surface). Note in passing that, as above explained, coverage beyond 0.5 ML is achievable depending on the water exposure. Furthermore, even coexistence of domains with different local coverage cannot be discarded. According to Figures 2 and 5, the $\mathrm{O}_{\mathrm{s}}-\mathrm{H}(000 \overline{1})$ species assignment seems the only possible from our data and it should be noted that contributions in the $3370-3450 \mathrm{~cm}^{-1}$ have been frequently observed at $\mathrm{ZnO}$ nanoparticles faceting polar surfaces. ${ }^{34,48-50}$ Nevertheless other unexplored situations (such as edges, kinks, etc.) were previously claimed as a possibility to assign such contribution. Thus, the assignment of the $3410 \mathrm{~cm}^{-1}$ presented in Figure 8 to a polar contribution seems highly likely although not conclusive.

Above $3500 \mathrm{~cm}^{-1}$ we can see signals from both polar $(000 \overline{1})$ and nonpolar $(10 \overline{1} 0)$ surfaces although the latter seems more important at higher wavenumbers. This fact becomes more evident with the treatment at higher temperature. However the high frequency peak displays relative small intensity and would require further analysis for definitive analysis of this region. Thus the uncertain assignment of peaks at this zone has been visually translated in overlapping colours in Figure 8.

\section{Summary and Outlook}

The present work presents an extensive and systematic computational study aimed at the identification, by means of simulated IR spectra, of hydroxyl and hydride species formed on the most stable low-index Miller surfaces of würtzite $\mathrm{ZnO}$, namely, the $\mathrm{Zn}$ - and O-

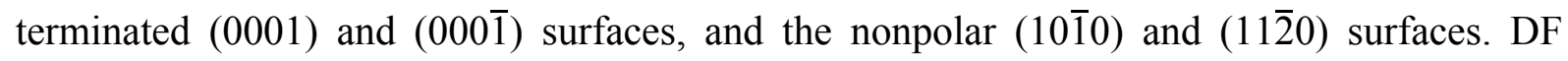
calculations at PBE level on slab models are found to adequately describe the surface structure and energetics, and to capture the interactions of atomic hydrogen, hydroxyl moieties, and water molecules adsorbed upon. All possible adsorption modes for $\mathrm{H}$ and $\mathrm{OH}$ moieties were studied on all surfaces at half and full coverage, and IR spectra were simulated 
for the most energetically favourable situations. The gained information was combined to study the most likely surface arrangements when $\mathrm{ZnO}$ systems are exposed to $\mathrm{H}_{2}$ or $\mathrm{H}_{2} \mathrm{O}$.

When dosing $\mathrm{H}_{2}$ to $\mathrm{ZnO}$ surfaces, both hydride and hydroxyl species are formed on the nonpolar surfaces, being an exothermic process by $\sim 50 \mathrm{~kJ} \mathrm{~mol}^{-1}$, and with IR-active peaks at $\sim 1800$ and $\sim 3600 \mathrm{~cm}^{-1}$, being both nonpolar surfaces nearly indistinguishable. The Oterminated $(000 \overline{1})$ surface is strongly attaching $\mathrm{H}$ adatoms, being the adsorption process exothermic by $194 \mathrm{~kJ} \mathrm{~mol}^{-1}$ and $152 \mathrm{~kJ} \mathrm{~mol}^{-1}$ at half and full coverage, respectively, with dominant IR $\mathrm{O}_{\mathrm{s}}-\mathrm{H}$ stretching peaks. The half coverage situation forming a $(1 \times 2)$ pattern is thermodynamically preferred, with a signal at $3744 \mathrm{~cm}^{-1}$, although a full coverage situation is feasible at moderate/high $\mathrm{H}_{2}$ pressures, with an estimated IR frequency of $3489 \mathrm{~cm}^{-1}$. Last but not least, formation of hydrides arranging in a $(1 \times 2)$ pattern is an isoenergetic process on (0001) surface, with $\mathrm{Zn}-\mathrm{H}$ stretching IR peaks at $1833 \mathrm{~cm}^{-1}$, while full coverage is an endothermic process, and so, a metastable situation with IR signal located at $1499 \mathrm{~cm}^{-1}$.

When dosing $\mathrm{H}_{2} \mathrm{O}$, the situation changes; a $(1 \times 2)$ pattern is clearly preferred adsorption energy of $286 \mathrm{~kJ} \mathrm{~mol}^{-1}$ — having hydroxyl and hydride moieties on $(000 \overline{1})$ and (0001) surfaces, respectively. This leads to additive IR signals at 3744 and $3755 \mathrm{~cm}^{-1}$, although the former signal is $\sim 100$ times more intense, and the only thought to be detectable. In any case, when dosing $\mathrm{H}_{2} \mathrm{O}$ to these surfaces, hydroxyl signals on nonpolar surfaces are the most intense: On the $(10 \overline{10})$ water arranges in a mixed dissociated state, with an adsorption energy of $112 \mathrm{~kJ}$ mol-1, in which the hydroxyls formed from water splitting feature a stretching frequency at $3765 \mathrm{~cm}^{-1}$, this is, an IR signal blue shifted from the polar surfaces. Furthermore, $\mathrm{H}$ adatoms formed from $\mathrm{H}_{2} \mathrm{O}$ partial dissociation produce surface hydroxyls with a characteristic IR stretching at $3159 \mathrm{~cm}^{-1}$. This mode is coupled with non-dissociated $\mathrm{H}_{2} \mathrm{O}$ stretching modes -2864 and $2994 \mathrm{~cm}^{-1}$ - forming a broad band. Finally, water is completely dissociated on the $(11 \overline{2} 0)$ surface, revealing two clearly distinguishable peaks at 
2587 and $3399 \mathrm{~cm}^{-1}$, belonging to surface $\mathrm{OH}$, and hydroxyls from dissociated water, respectively.

The combination of experimental and theoretical methods does not only allow one to discriminate among different water-related species in IR studies concerning model surfaces, but also in photocatalytically relevant $\mathrm{ZnO}$ nanoparticles. A very important finding is that experimental frequency regions between $3100-3370$ and $3370-3500 \mathrm{~cm}^{-1}$ seems distinctive of nonpolar and polar surfaces, respectively, and would thus allow to identify the dominance of such type of surfaces at in situ conditions where the application of microscopy or other techniques is rather complex. This indicates that IR is a powerful tool in describing shape and surface morphology of $\mathrm{ZnO}$ nanostructures and allows to follow active surface sites under reaction conditions.

\section{Acknowledgements}

This work was supported by the Spanish MICINN (grants FIS2008-02238, CTQ2012-30751, and CTQ-2010-14872/BQU) and, in part, by the Generalitat de Catalunya (grants 2009SGR1041 and XRQTC). F.V. thanks the MINECO for a postdoctoral Juan de la Cierva grant (JCI-2010-06372), A.I.-J. thanks the Ramón y Cajal program (MINECO, Spain) for a postdoctoral fellowship, and F.I acknowledges additional funding through the 2009 ICREA Academia award. This work is also part of COST Action CM1104.

Supporting Information Available: Figure S1 depicts the IR spectra of Figure 7 but assuming decomposition into five Gaussian contributions. A justification of using eight contributions is provided, as well as $F$-test of the variance for the IR fittings, shown in Table $\mathrm{S} 1 . \mathrm{ZnO}$ bulk and surface calculations are commented and compared to experimental values, see Table S2. A sketch of the different surfaces employed is shown in Figure S2. This material is available free of charge via the Internet at http://pubs.acs.org. 


\section{References}

(1) Mang, A.; Reimann, K.; Rübenacke, S. Band Gaps, Crystal-Field Splitting, Spin-Orbit Coupling, and Exciton Binding Energies in $\mathrm{ZnO}$ under Hydrostatic Pressure. Solid State Commun. 1995, 94, 251-254.

(2) Reynolds, D. C.; Look, D. C.; Jogai, B.; Litton, C. W.; Cantwell, G.; Harsch, W. C. Valence-Band Ordering in ZnO. Phys. Rev. B 1999, 60, 2340-2344.

(3) Van de Walle, C. G.; Janotti, A. Fundamentals of Zinc Oxide as a Semiconductor. Rep. Prog. Phys. 2009, 72, 126501.

(4) Goldberger, J.; Sirbuly, D. J.; Law, M.; Yang, P. ZnO Nanowire Transistors. J. Phys. Chem. B 2005, 109, 9-14.

(5) Kind, H.; Yan, H. Q.; Messer, B.; Law, M.; Yang, P. D. Nanowire Ultraviolet Photodetectors and Optical Switches. Adv. Mater. 2002, 14, 158-160.

(6) Colvin, V. L.; Schlamp, M. C.; Alivisatos, A. P. Light-Emitting Diodes Made from Cadmium Selenide Nanocrystals and a Semiconducting Polymer. Nature 1994, 370, 354-357.

(7) Huang, M. H.; Mao, S.; Feick, H.; Yan, H. Q.; Wu, Y. Y.; Kind, H.; Weber, E.; Russo, R.; Yang, P. D. Room-Temperature Ultraviolet Nanowire Nanolasers. Science 2001, 292, 1897-1899.

(8) Rout, C. S.; Raju, A. R.; Govindaraj, A.; Rao, C. N. R. Hydrogen Sensors Based on ZnO Nanoparticles. Solid State Commun. 2006, 138, 136-138.

(9) Wang, Z. L.; Song, J. H. Piezoelectric Nanogenerators Based on Zinc Oxide Nanowire Arrays. Science 2006, 312, 242-246.

(10) Duran, P. ; Capel, F.; Tartaj, J.; Moure, C. A Strategic Two-Stage Low-Temperature Thermal Processing Leading to Fully Dense and Fine-Grained Doped-ZnO Varistors. Adv. Mater. 2002, 14, 137-141.

(11) Marczak, R.; Werner, F.; Ahmad, R.; Lobaz, V.; Guldi, D. M.; Peukert, W. Detailed Investigations of $\mathrm{ZnO}$ Photoelectrodes Preparation for Dye Sensitized Solar Cells. Langmuir 2011, 27, 3920-3929.

(12) O’Regan, B.; Grätzel, M. A Low-Cost, High-Efficiency Solar Cell Based on DyeSensitized Colloidal $\mathrm{TiO}_{2}$ Films. Nature 1991, 353, 737-739.

(13) Polarz, S.; Strunk, J.; Ischenko, V.; van den Berg, M. W. E.; Hinrichsen, O.; Muhler, M. ; Driess, M. On the Role of Oxygen Defects in the Catalytic Performance of Zinc Oxide. Angew. Chem. Int. Ed. 2006, 45, 2965-1969. 
(14) French, S. A.; Sokol, A. A.; Bromley, S. T.; Catlow, C. R. A.; Rogers, S. C.; King, F.; Sherwood, P. From $\mathrm{CO}_{2}$ to Methanol by Hybrid QM/MM Embedding. Angew. Chem. Int. Ed. 2001, 40, 4437-4440.

(15) Kurtz, M.; Strunk, J.; Hinrichsen, O.; Muhler, M.; Fink, K.; Meyer, B.; Wöll, C. Active Sites on Oxide Surfaces: ZnO-Catalyzed Synthesis of Methanol from $\mathrm{CO}$ and $\mathrm{H}_{2}$. Angew. Chem. Int. Ed. 2005, 44, 2790-2794.

(16) Meyer, B.; Marx, D.; Dulub, O.; Diebold, U.; Kunat, M.; Langenberg, D.; Wöll, C. Partial Dissociation of Water Leads to Stable Superstructures on the Surface of Zinc Oxide. Angew. Chem. Int. Ed. 2004, 43, 6642-6645.

(17) Rodriguez, J. A.; Maiti, A. Adsorption and Decomposition of $\mathrm{H}_{2} \mathrm{~S}$ on $\mathrm{MgO}(100)$, NiMgO(100), and ZnO(0001) Surfaces: A First-Principles Density Functional Study. $J$. Phys. Chem. B 2000, 104, 3630-3638.

(18) Jirsak, T.; Dvorak, J.; Rodriguez, J. A. Chemistry of Thiophene on ZnO, S/ZnO, and $\mathrm{Cs} / \mathrm{ZnO}$ Surfaces: Effects of Cesium on Desulfurization Processes. J. Phys. Chem. B 1999, 103, 5550-5559.

(19) Dvorak, J.; Jirsak, T.; Rodriguez, J. A. Fundamental Studies of Desulfurization Processes: Reaction of Methanethiol on ZnO and Cs/ZnO. Surf. Sci. 2001, 479, 155 168.

(20) Hinrichsen, O.; Kochlöfl, K.; Muhler, M. in Handbook of Heterogeneous Catalysis $2^{\text {nd }}$ ed. (Eds. G. Ertl, H. Knözinger, J. Weitkamp) VCH, Weinheim, Germany, 2008.

(21) Wang, Y.; Kováčik, R.; Meyer, B.; Kotsis, K.; Stodt, D.; Stämmler, V.; Qiu, H.; Träger, F.; Langenberg, D.; Muhler, M. et al. Tuning the Reactivity of Oxide Surfaces by Charge-Accepting Adsorbates. Angew. Chem. Int. Ed. 2007, 46, 7315-7318.

(22) Messori, M.; Vaccari, A. Reaction Pathway in Vapor Phase Hydrogenation of Maleic Anhydride and Its Esters to $\gamma$-Butyrolactone. J. Catal. 1994, 150, 177-185.

(23) Mclaren, A.; Valdes-Solis, T.; Li, G.; Tsang, S. C. Shape and Size Effects of ZnO Nanocrystals on Photocatalytic Activity. J. Am. Chem. Soc. 2009, 131, 12540-12541.

(24) Pauporte, T.; Rathousky, J. Electrodeposited Mesoporous ZnO Thin Films as Efficient Photocatalysts for the Degradation of Dye Pollutants. J. Phys. Chem. C 2007, 111, 7639-7644.

(25) Tian, Z. R.; Voigt, J. A.; Liu, J.; McKenzie, B.; McDermott, M. J.; Rodriguez, M. A.; Konishi, H.; Xu, H. Complex and Oriented ZnO Nanostructures. Nat. Mater. 2003, 2 , $821-826$. 
(26) Kormann, C.; Bahnemann, D. W.; Hoffmann, M. R. Photocatalytic Production of Hydrogen Peroxides and Organic Peroxides in Aqueous Suspensions of Titanium Dioxide, Zinc Oxide, and Desert Sand. Environ. Sci. Technol. 1988, 22, 798-806.

(27) Maeda, K.; Domen, K. Solid Solution of GaN and $\mathrm{ZnO}$ as a Stable Photocatalyst for Overall Water Splitting under Visible Light. Chem. Mater. 2010, 22, 612-623.

(28) Khodja, A. A.; Sehili, T.; Pilichowski, J. F.; Boule, P. Photocatalytic Degradation of 2Phenylphenol on $\mathrm{TiO}_{2}$ and $\mathrm{ZnO}$ in Aqueous Suspensions. J. Photochem. Photobiol. A: Chem. 2001, 141, 231-239.

(29) Xu, L.; Hu, Y. L.; Pelligra, C.; Chen, C. H.; Jin, L.; Huang, H.; Sithambaram, S.; Aindow, M.; Joesten, R.; Suib, S. L. ZnO with Different Morphologies Synthesized by Solvothermal Methods for Enhanced Photocatalytic Activity. Chem. Mater. 2009, 21, 2875-2885.

(30) Kislov, N.; Lahiri, J.; Verma, H.; Goswanni, D. Y.; Stefanakos, E.; Batzill, M. Photocatalytic Degradation of Methyl Orange over Single Crystalline ZnO: Orientation Dependence of Photoactivity and Photostability of ZnO. Langmuir 2009, 25, 33103315.

(31) Li, G. R.; Hu, T.; Pan, G. L.; Yan, T. Y.; Gao, X. P.; Zhu, H. Y. Morphology-Function Relationship of ZnO: Polar Planes, Oxygen Vacancies, and Activity. J. Phys. Chem. C 2008, 112, 11859-11864.

(32) Wang, Z. L. Splendid One-Dimensional Nanostructures of Zinc Oxide: A New Nanomaterial Family for Nanotechnology. ACS Nano 2008, 2, 1987-1992.

(33) Lizandara-Pueyo, C.; Siroky, S.; Wagner, M. R.; Hoffman, A.; Reparaz, J. S.; Lehmann, M.; Polarz, S. Shape Anisotropy Influencing Functional Properties: Trigonal Prismatic ZnO Nanoparticles as an Example. Adv. Funct. Mater. 2011, 21, 295-304.

(34) Noei, H.; Qiu, H.; Wang, Y.; Mühler, M.; Wöll, C. Hydrogen Loading of Oxide Powder Particles: A Transmission IR Study for the Case of Zinc Oxide. ChemPhysChem 2010, 11, 3604-3607.

(35) Richard, C.; Bosquet, F.; Pilichowski, J.-F. Photocatalytic Transformation of Aromatic Compounds in Aqueous Zinc Oxide Suspensions: Effect of Substrate Concentration on the Distribution of Products. J. Photochem. Photobiol. A: Chem. 1997, 108, 45-49.

(36) Richard, C.; Boule, P. Reactive Species Involved in Photocatalytic Transformations on Zinc Oxide. Sol. Energy Mater. Sol. Cells 1995, 38, 431-440. 
(37) Kulkarni, D.; Wachs, I. E. Isopropanol Oxidation by Pure Metal Oxide Catalysts: Number of Active Surface Sites and Turnover Frequencies. Appl. Catal. A: General 2002, 237, 121-137.

(38) Wang, Y.; Wöll, C. Chemical Reactions on Metal Oxide Surfaces Investigated by Vibrational Spectroscopy. Surf. Sci. 2009, 603, 1589-1599.

(39) Strunk, J.; Kähler, K.; Xia, X.; Muhler, M. The Surface Chemistry of ZnO Nanoparticles Applied as Heterogeneous Catalysts in Methanol Synthesis. Surf. Sci. 2009, 603, 1776-1783.

(40) Clotet, A.; Valcarcel, A.; Ricart, J. M.; Illas, F. Theoretical Interpretation of the IR Spectrum of Propyne on $\mathrm{Cu}(111)$. J. Phys. Chem. B 2004, 108, 18297-18305.

(41) Desikusumastuti, A.; Staudt, T.; Grönbeck, H.; Libuda, J. Identifying Surface Species by Vibrational Spectroscopy: Bridging vs Monodentate Nitrates. J. Catal. 2008, 255, 127-133.

(42) Happel, M.; Luckas, N.; Viñes, F.; Sobota, M.; Laurin, M.; Görling, A.; Libuda, J. SO 2 Adsorption on Pt(111) and Oxygen Precovered Pt(111): A Combined Infrared Reflection Absorption Spectroscopy and Density Functional Study. J. Phys. Chem. C 2011, 115, 479-491.

(43) Luckas, N.; Viñes, F.; Happel, M.; Desikusumastuti, A.; Libuda, J.; Görling, A. Density Functional Calculations and IR Reflection Absorption Spectroscopy on the Interaction of $\mathrm{SO}_{2}$ with Oxide-Supported Pd Nanoparticles. J. Phys. Chem. C 2010, 114, 1381313824.

(44) Wang, Y. High Resolution Electron Energy Loss Spectroscopy on Perfect and Defective Oxide Surfaces. Z. Phys. Chem. 2008, 222, 927-964.

(45) Wang, Y.; Meyer, B.; Yin, X.; Kunat, M.; Langenberg, D.; Traeger, F.; Birkner, A.; Wöll, C. Hydrogen Induced Metallicity on the $\mathrm{ZnO}(10 \overline{10})$ Surface. Phys. Rev. Lett. 2005, 95, 266104.

(46) Wang, Y.; Muhler, M.; Wöll, C. Spectroscopic Evidence for the Partial Dissociation of $\mathrm{H}_{2} \mathrm{O}$ on $\mathrm{ZnO}(10 \overline{1} 0)$. Phys. Chem. Chem. Phys. 2006, 8, 1521-1524.

(47) Noei, H.; Qiu, H.; Wang, Y.; Löffler, E.; Wöll, C.; Mühler, M. The Identification of Hydroxyl Groups on ZnO Nanoparticles by Infrared Spectroscopy. Phys. Chem. Chem. Phys. 2008, 10, 7092-7097.

(48) Eischens, R. P.; Pliskin, W. A.; Low, M. J. D. The Infrared Spectrum of Hydrogen Chemisorbed on Zinc Oxide. J. Catal. 1962, 1, 180-191. 
(49) Boccuzzi, F.; Borello, E.; Zecchina, A.; Bossi, A.; Camia, M. Infrared Study of ZnO Surface Properties: I. Hydrogen and Deuterium Chemisorption at Room Temperature. $J$. Catal. 1978, 51, 150-159.

(50) Griffin, G. L.; Yates Jr., J. T. Adsorption Studies of $\mathrm{H}_{2}$ Isotopes on $\mathrm{ZnO}$ : Coverage-Induced IR Frequency Shifts and Adsorbate Geometry. J. Chem. Phys. 1982, 77, 3744-3750.

(51) Dulub, O.; Diebold, U.; Kresse, G. Novel Stabilization Mechanism on Polar Surfaces: ZnO(0001)-Zn. Phys. Rev. Lett. 2003, 90, 016102.

(52) Meyer, B. First-Principles Study of the Polar O-Terminated $\mathrm{ZnO}$ Surface in Thermodynamic Equilibrium with Oxygen and Hydrogen. Phys. Rev. B 2004, 69, 045416 .

(53) Kresse, G.; Dulub, O.; Diebold, U. Competing Stabilization Mechanism for the Polar $\mathrm{ZnO}(0001)-\mathrm{Zn}$ surface. Phys. Rev. B 2003, 68, 245409.

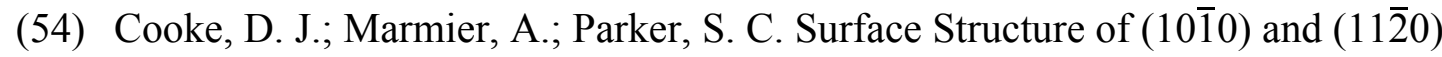
Surfaces of $\mathrm{ZnO}$ with Density Functional Theory and Atomistic Simulation. J. Phys. Chem. B 2006, 110, 7985-7991.

(55) Lauritsen, J. V.; Porsgaard, S.; Rasmussen, M. K.; Jensen, M. C. R.; Bechstein, R.; Meinander, K.; Clausen, B. S.; Helveg, S.; Wahl, R.; Kresse, G.; et al. Stabilization Principles for Polar Surfaces of ZnO. ACS Nano 2011, 5, 5987-5994.

(56) Kresse, G.; Furthmüller, J. Efficient Iterative Schemes for Ab Initio Total-Energy Calculations Using a Plane-Wave Basis Set. Phys. Rev. B 1996, 54, 11169-11186.

(57) Blöchl, P. E. Projector Augmented-Wave Method. Phys. Rev. B 1994, 50, 17953-17979.

(58) Perdew, J. P.; Burke, K.; Ernzerhof, M. Generalized Gradient Approximation Made Simple. Phys. Rev. Lett. 1996, 77, 3865-3868.

(59) Meyer, B.; Marx, D. Density-Functional Study of the Structure and Stability of ZnO Surfaces. Phys. Rev. B 2003, 67, 035403.

(60) Moreira, N. H.; Dolgonos, G.; Aradi, B.; da Rosa, A. L.; Frauenheim, T. Toward an Accurate Density-Functional Tight-Binding Description of Zinc-Containing Compounds. J. Chem. Theo. Comput. 2009, 5, 605-614.

(61) Meyer, B.; Rabaa, H.; Marx, D. Water Adsorption on $\mathrm{ZnO}(10 \overline{1} 0)$ : From Single Molecules to Partially Dissociated Monolayers. Phys. Chem. Chem. Phys. 2006, 8, 1513-1520. 
(62) Goniakowski, J.; Finocchi, F.; Noguera, C. Polarity of Oxide Surfaces and Nanostructures. Rep. Prog. Phys. 2008, 71, 016501.

(63) Noguera, C. Polar Oxide Surfaces. J. Phys.: Condens. Matter 2000, 12, R367-R410.

(64) Wander, A.; Schedin, F.; Steadman, P.; Norris, A.; McGrath, R.; Turner, T. S.; Thornton, G.; Harrison, N. M. Stability of Polar Oxide Surfaces. Phys. Rev. Lett. 2001, 86, 3811-3814.

(65) Fan, W.; Xu, H.; Rosa, A. L.; Frauenheim, T.; Zhang, R. Q. First-Principles Calculations of Reconstructed [0001] ZnO Nanowires. Phys. Rev. B 2007, 76, 073302.

(66) Jedrecy, N.; Galllini, S.; Sauvage-Simkin, M.; Pinchaux, R. The ZnO Non-Polar (10̄̄0) Surface: an X-Ray Structural Investigation. Surf. Sci. 2000, 460, 136-143.

(67) Kunat, M.; Gil-Girol, S.; Becker, T.; Burghaus, U.; Wöll, C. Stability of the Polar Surfaces of ZnO: A Reinvestigation Using He-Atom Scattering. Phys. Rev. B 2002, 66, 081402 .

(68) Becker, T.; Hövel, S.; Kunat, M.; Boas, C.; Burghaus, U.; Wöll, C. Interaction of Hydrogen with Metal Oxides: the Case of the Polar ZnO(0001) Surface. Surf. Sci. 2001, 486, L502-L506.

(69) Dulub, O.; Meyer, B.; Diebold, U. Observation of the Dynamical Change in a Water Monolayer Adsorbed on a ZnO Surface. Phys. Rev. Lett. 2005, 95, 136101.

(70) Nénon, S.; Méreau, R.; Salman, S.; Castet, F.; Regemorter, T. V.; Clima, S.; Beljonne, D.; Cornil, J. Structural and Electronic Properties of the TTF/ZnO(1010) Interface: Insights From Modeling. J. Phys. Chem. Lett. 2012, 3, 58-63.

(71) Wander, A.; Harrison, N. M. The structure of higher defective $\mathrm{ZnO}(1010)$. Surf. Sci. 2003, 529, 281-284.

(72) Wander, A.; Harrison, N. M. The stability of polar oxide surfaces: The Interaction of $\mathrm{H}_{2} \mathrm{O}$ with $\mathrm{ZnO}(0001)$ and $\mathrm{ZnO}(000 \overline{1})$. J. Chem. Phys. 2001, 115, 2312-2316.

(73) Chang, C. C.; Dixon, L. T.; Kokes, R. J. Adsorption Studies of $\mathrm{H}_{2}$ Isotopes on ZnO: Coverage-Induced IR Frequency Shifts and Adsorbate Geometry. J. Phys. Chem. 1982, 77, 3744-3750.

(74) Barański, A.; Gałuszka, J. Temperature-Programmed Desorption Studies of the Hydrogen-Zinc Oxide System. J. Catal. 1976, 44, 259-270.

(75) Damen, T. C.; Porto, S. P. S.; Tell, B. Raman Effect in Zinc Oxide. Phys. Rev. 1966, $142,570-574$. 
(76) Arguello, C. A.; Rousseau, D. L.; Porto, S. P. S. First-Order Raman Effect in WurtziteType Crystals. Phys. Rev. 1969, 181, 1351-1354.

(77) Bairamov, B. H.; Heinrich, A.; Irmer, G.; Toporov, V. V.; Ziegler, E. Raman Study of the Phonon Halfwidths and the Phonon-Plasmon Coupling in ZnO. Phys. Stat. Sol. B 1983, 119, 227-234.

(78) Valcarcel, A.; Ricart, J. M.; Illas, F.; Clotet, A. Theoretical Interpretation of the IR Spectrum of Propyne on $\mathrm{Cu}(111)$. J. Phys. Chem. B 2004, 108, 18297-18305.

(79) Haubrich, J.; Loffreda, D.; Delbecq, F.; Jugnet, Y.; Sautet, P.; Krupski, A.; Becker, C.; Wandelt, K. Determination of the Crotonaldehyde Structures on Pt and PtSn Surface Alloys from a Combined Experimental and Theoretical. Chem. Phys. Lett. 2006, 433, 188-192.

(80) Carrasco, J.; Michaelides, A.; Forster, M.; Haq, S.; Raval, R.; Hodgson, A. A OneDimensional Ice Structure Built from Pentagons. Nat. Mater. 2009, 8, 427-431.

(81) Yang, Z.; Li, Q.; Hua, R.; Gray, M. R.; Chouk, K. G. Competitive Adsorption of Toluene and $n$-Alkanes at Binary Solution/Silica Interfaces. J. Phys. Chem. C 2009, $113,20355-20359$.

(82) Aliaga, C.; Baldelli, S. A Sum Frequency Generation Study of the Room-Temperature Ionic Liquid-Titanium Dioxide Interface. J. Phys. Chem. C 2008, 112, 3064-3072.

(83) Decremps, F.; Datchi, F.; Saitta, A. M.; Polian, A.; Pascarelli, S.; Di Cicco, A.; Itié, J. P.; Baudelet, F. Local Structure of Condensed Zinc Oxide. Phys. Rev. B 2003, 68, 104101.

(84) Jaffe, J. E.; Snyder, J. A.; Lin, Z.; Hess, A. C. Structures and Electronic Properties of Small Carbon Nanotube Tori. Phys. Rev. B 2000, 62, 1600-1665.

(85) He, M.-R.; Yu, R.; Zhu J. Subangstrom Profile Imaging of Relaxed ZnO(10̄̄0) Surfaces. Nano Lett. 2012, 12, 704-708.

(86) Duke, C. B.; Meyer, R. J.; Paton, A.; Mark, P. Calculation of Low-Energy-ElectronDiffraction Intensities from $\mathrm{ZnO}(10 \overline{1} 0)$. II. Influence of Calculational Procedure, Model Potential, and Second-Layer Structural Distortions. Phys. Rev. B 1978, 18, 4225-4240.

(87) Ding, Y.; Wang, Z. L. Profile Imaging of Reconstructed Polar and Non-Polar Surfaces of ZnO. Surf. Sci. 2007, 601, 425-433.

(88) Göpel, W.; Pollman, J.; Ivanov, I.; Reihl, B. Angle-Resolved Photoemission from Polar and Nonpolar Zinc Oxide Surfaces. Phys. Rev. B 1982, 26, 3144-3150. 
(89) Jedrecy, N.; Gallini, S.; Sauvage-Simkin, M.; Pinchaux, R. Copper Growth on the OTerminated $\mathrm{ZnO}(000 \overline{1})$ Surface: Structure and Morphology. Phys. Rev. B 2001, 64, 085424 .

(90) Kotsis, K.; Stämmler, V. Ab Initio Calculations of the O1s XPS Spectra of ZnO and Zn Oxo Compounds. Phys. Chem. Chem. Phys. 2006, 8, 1490-1498.

(91) Schiek, M.; Al-Shamery, A.; Kunat, M.; Traeger, F.; Wöll, C. Water Adsorption on the Hydroxylated H-(1×1) O-ZnO(0001) Surface. Phys. Chem. Chem. Phys. 2006, 8, 15051512.

(92) Valtiner, M.; Todorova, M.; Neugebauer, J. Hydrogen Adsorption on Polar ZnO(0001)Zn: Extending Equilibrium Surface Phase Diagrams to Kinetically Stabilized Structures. Phys. Rev. B 2010, 82, 165418.

(93) Batyrev, E. D.; van den Heuvel, J. C. Modification of the $\mathrm{ZnO}(0001)-\mathrm{Zn}$ Surface Under Reducing Conditions. Phys. Chem. Chem. Phys. 2011, 13, 13127-13134.

(94) Sánchez, N.; Gallego, S.; Cerdá, J.; Muñoz, M. C. Tuning Surface Metallicity and Ferromagnetism by Hydrogen Adsorption at the Polar $\mathrm{ZnO}(0001)$ Surface. Phys. Rev. B 2010, $81,115301$.

(95) Yin, X. L.; Birkner, A.; Hänel, K.; Löber, T.; Köhler, U.; Wöll, C. Adsorption of Atomic Hydrogen on ZnO(1010): STM Study. Phys. Chem. Chem. Phys. 2006, 8, 14771481.

(96) Ozawa, K.; Mase, K. Comparison of the Surface Electronic Structures of H-Adsorbed ZnO Surfaces: An Angle-Resolved Photoelectron Spectroscopy Study. Phys. Rev. B 2011, 83, 125406.

(97) Ozawa, K.; Mase, K. Metallization of $\mathrm{ZnO}(10 \overline{1} 0)$ by Adsorption of Hydrogen, Methanol, and Water: Angle-Resolved Photoelectron Spectroscopy. Phys. Rev. B 2010, $81,205322$.

(98) Wander, A.; Harrison, N. M. An Ab Initio Study of Hydrogen Adsorption on $\mathrm{ZnO}(10 \overline{1} 0)$. J. Phys. Chem. B 2001, 105, 6191-6193.

(99) Nyberg, M.; Nygren, M. A.; Pettersson, L. G. M.; Gay, D. H.; Rohl, A. L. Hydrogen Dissociation on Reconstructed ZnO Surfaces. J. Phys. Chem. 1996, 100, 9054.

(100) Martins, J. B. L.; Taft, C. A.; Longo, E.; de Castro, E. A. S.; da Cunha, W. F.; Politi, J. R. S.; Gargano, R. ONIOM Study of Dissociated Hydrogen and Water on ZnO Surface. Int. J. Quantum Chem. 2012, 112, 3223-3227. 
(101) Meyer, B.; Marx, D. Density-Functional Study of the Structure and Stability of ZnO Surfaces. Phys. Rev. B 2003, 67, 035403.

(102) French, S. A.; Sokol, A. A.; Bromley, S. T.; Catlow, C. R. A.; Rogers, S. C.; Sherwood, P. Assignment of the Complex Vibrational Spectra of the Hydrogenated ZnO Polar Surfaces Using QM/MM Embedding. J. Chem. Phys. 2003, 118, 317-320.

(103) Catlow, C. R. A.; French, S. A.; Sokol, A. A.; Al-Sunadi, A. A.; Woodley, S. M. Zinc Oxide: A Case Study in Contemporary Computational Solid State Chemistry. J. Comput. Chem. 2008, 29, 2234-2249.

(104) Scarano, D.; Spoto, G.; Bordiga, S.; Zecchina, A.; Lamberti, C. Lateral Interactions in CO Adlayers on Prismatic ZnO faces: A FTIR and HRTEM Study. Surf. Sci. 1992, 276, 281-298.

(105) Kunat, S. G.; Girol, U.; Burghaus, U.; Wöll, C. The Interaction of Water with the Oxygen-Terminated, Polar Surface of ZnO. J. Phys. Chem. B 2003, 107, 14350-14356. (106) Raymand, D.; van Duin, A. C. T.; Spangberg, D.; Goddard III, W. A.; Hermansson, K. Water Adsorption on Stepped ZnO Surfaces from MD Simulation. Surf. Sci. 2010, 604, 741-752.

(107) Lamberti, C.; Zecchina, A.; Groppo, E.; Bordiga, S. Probing the Surfaces of Heterogeneous Catalysts by in Situ IR Spectroscopy. Chem. Soc. Rev. 2010, 39, 49515001 .

(108) Kuchitsu, K.; Morino, Y. Estimation of Anharmonic Potential Constants. II. Bent XY2 Molecules. Bull. Chem. Soc. Jpn. 1965, 38, 814-824. 
Table 1: Structural (bond length $\delta$, and angle respect to surface plane $\alpha$ ), energetic (adsorption energy $\mathrm{E}_{\mathrm{ads}}$ ), and vibrational (frequency $v$ ) data for the $\mathrm{H}$ adsorption on $\mathrm{ZnO}$ surfaces as $\mathrm{Zn}-\mathrm{H}$ or $\mathrm{O}_{\mathrm{s}}-\mathrm{H}$ moieties at different coverage. Notice that coadsorption situation belongs to cases where $\mathrm{Zn}-\mathrm{H}$ and $\mathrm{O}_{\mathrm{s}}-\mathrm{H}$ species are simultaneously coexisting, both at full coverage.

\begin{tabular}{|c|c|c|c|c|c|}
\hline & & $\begin{array}{c}\delta \\
\mathrm{pm}\end{array}$ & $\begin{array}{c}\alpha \\
\mathrm{o}\end{array}$ & $\begin{array}{c}\mathbf{E}_{\mathbf{a d s}} \\
\mathrm{kJ} \mathrm{mol}^{-1}\end{array}$ & $\begin{array}{c}\boldsymbol{v} \\
\mathrm{cm}^{-1}\end{array}$ \\
\hline & & \multicolumn{4}{|c|}{$0.5 \mathrm{ML}$} \\
\hline \multirow[t]{2}{*}{ Zn-H } & (0001) & 155 & 88.6 & 216 & 1833 \\
\hline & $(000 \overline{1})$ & 97 & 88.6 & 412 & 3744 \\
\hline \multirow[t]{3}{*}{$\mathrm{O}_{\mathrm{s}}-\mathrm{H}$} & $(\mathbf{1 0 1 0} 0)$ & 98 & 74.5 & 231 & 3630 \\
\hline & $(11 \overline{2} 0)$ & 98 & 55.8 & 202 & 3569 \\
\hline & & \multicolumn{4}{|c|}{$1 \mathrm{ML}$} \\
\hline \multirow[t]{2}{*}{ Zn-H } & $(0001)$ & 160 & 89.6 & 119 & 1499 \\
\hline & $(000 \overline{1})$ & 99 & 89.9 & 294 & 3489 \\
\hline \multirow[t]{3}{*}{$\mathrm{O}_{\mathrm{s}}-\mathbf{H}$} & $(\mathbf{1 0 1 0} 0)$ & 98 & 66.1 & 208 & 3586 \\
\hline & $(11 \overline{2} 0)$ & 99 & 49.2 & 196 & 3495 \\
\hline & & \multicolumn{4}{|c|}{ Coadsorption } \\
\hline \multirow{2}{*}{ Zn-H } & $(10 \overline{10})$ & 156 & 67.8 & 261 & 1797 \\
\hline & $(11 \overline{2} 0)$ & 156 & 56.7 & 265 & 1814 \\
\hline \multirow{2}{*}{$\mathrm{O}_{\mathrm{s}}-\mathrm{H}$} & $(\mathbf{1 0 1 0})$ & 98 & 63.6 & 261 & 3601 \\
\hline & $(11 \overline{2} 0)$ & 98 & 53.0 & 265 & 3606 \\
\hline
\end{tabular}


Table 2: Structural (bond length $\delta$, and angle respect to surface plane $\alpha$ ), energetic (adsorption energy $\mathrm{E}_{\mathrm{ads}}$ ), and vibrational (frequency $v$ ) data for the adsorption of $\mathrm{OH}$ moieties on $\mathrm{ZnO}$ surfaces at different coverages.

\begin{tabular}{|c|c|c|c|c|c|c|c|c|c|}
\hline & & \multicolumn{4}{|c|}{$0.5 \mathrm{ML}$} & \multicolumn{4}{|c|}{$1.0 \mathrm{ML}$} \\
\hline & & $\delta$ & $\alpha$ & $\mathbf{E}_{\mathbf{a d s}}$ & $v$ & $\delta$ & $\alpha$ & $\mathbf{E}_{\text {ads }}$ & $v$ \\
\hline & & $\mathrm{pm}$ & o & $\begin{array}{c}\mathrm{kJ} \\
\mathrm{mol}^{-1}\end{array}$ & $\mathrm{~cm}^{-1}$ & $\mathrm{pm}$ & o & $\begin{array}{c}\mathrm{kJ} \\
\mathrm{mol}^{-1}\end{array}$ & $\mathrm{~cm}^{-1}$ \\
\hline (0001) & $\mu^{3}$ & 97 & 83.0 & 393 & 3755 & 97 & 89.8 & 274 & 3744 \\
\hline$(000 \overline{1})$ & $\eta^{2}$ & 99 & 11.9 & 148 & 3552 & $98^{\mathrm{a}}$ & $104.4^{\mathrm{a}}$ & 144 & $3683 / 3506$ \\
\hline \multirow{2}{*}{$(10 \overline{10})$} & $\mu^{2}$ & 98 & 38.3 & 172 & 3721 & 97 & 49.4 & 163 & 3736 \\
\hline & $\mu^{1}$ & 98 & 0.7 & 166 & 3699 & 98 & 20.2 & 159 & 3631 \\
\hline \multirow{2}{*}{ (112̄0) } & $\eta^{2}$ & 99 & -16.3 & 133 & 3503 & 99 & 12.8 & 144 & 3366 \\
\hline & $\eta^{1}$ & 97 & 43.3 & 131 & 3733 & 98 & 15.6 & 130 & 3660 \\
\hline
\end{tabular}

${ }^{\mathrm{a}}$ Spontaneous $\mathrm{H}_{2} \mathrm{O}$ formation, and $\mathrm{O}-\mathrm{O}_{\mathrm{s}}$ bond of $134 \mathrm{pm}$. 
Table 3: Structural (Hydroxyl bond lengths $\delta$, water bond lengths $\delta^{1}$ and $\delta^{2}$, hydroxyl angle respect to surface plane $\alpha$, and water molecule angel $\beta$ ), energetic (adsorption energy $E_{\text {ads }}$ ), and vibrational (frequency $v$ ) data for partially- and fully-dissociated $\mathrm{H}_{2} \mathrm{O}$ adsorption

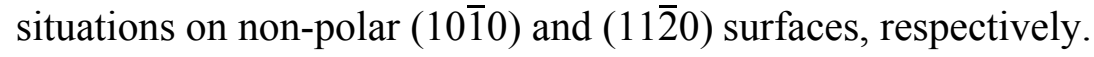

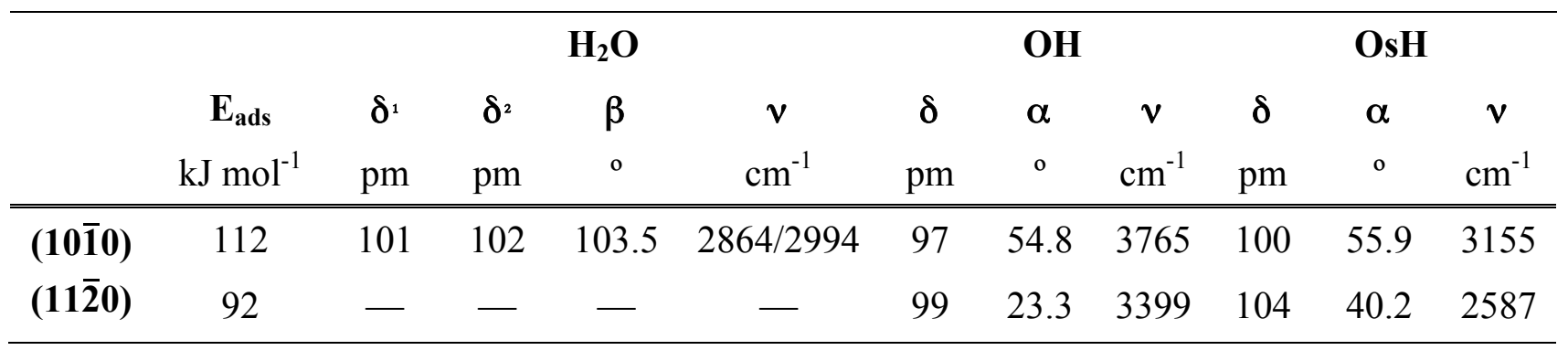


Figure 1: Crystallographic $\mathrm{ZnO}$ würtzite structure. Preferential surface orientations are displayed with coloured planes and direction vectors for the hexagonal (upper image) and the orthorhombic (bottom image) unit cells. Orange and iceblue spheres denote Oxygen and Zinc atoms, respectively.
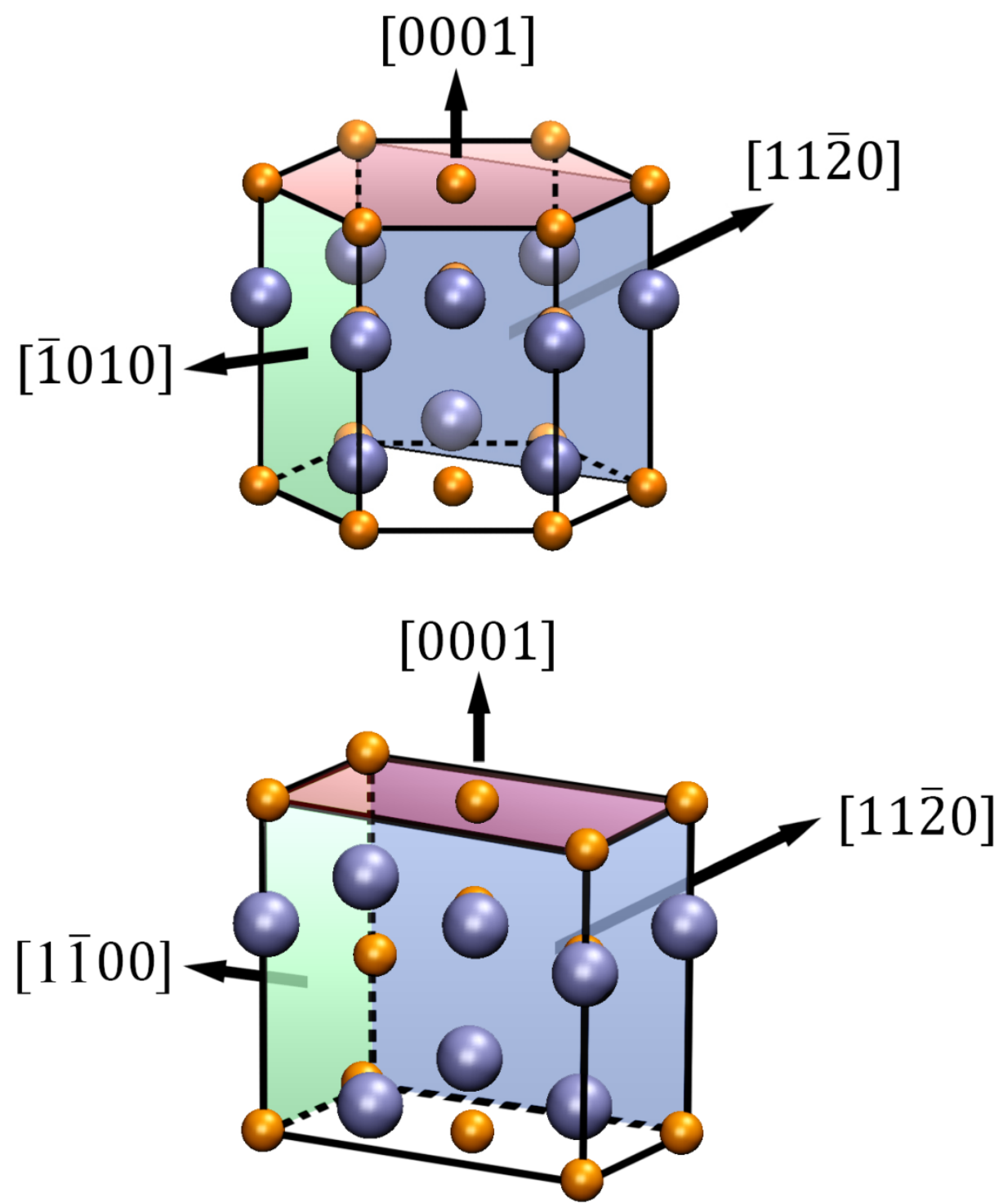
Figure 2: Simulated IR spectra of $\mathrm{H}$ adsorption on different $\mathrm{ZnO}$ surfaces at 0.5 (right peaks) and 1 ML (left peaks) coverage. Vibrational frequencies (numerical values summarized in Table 1) of $\mathrm{Zn}-\mathrm{H}$ are referred to the top blue axis while for $\mathrm{O}_{\mathrm{s}}-\mathrm{H}$ species to the down black axis. Weak peak intensities have been zoomed by a factor shown at each panel. $\mathrm{H}$ atoms are represented by white spheres.

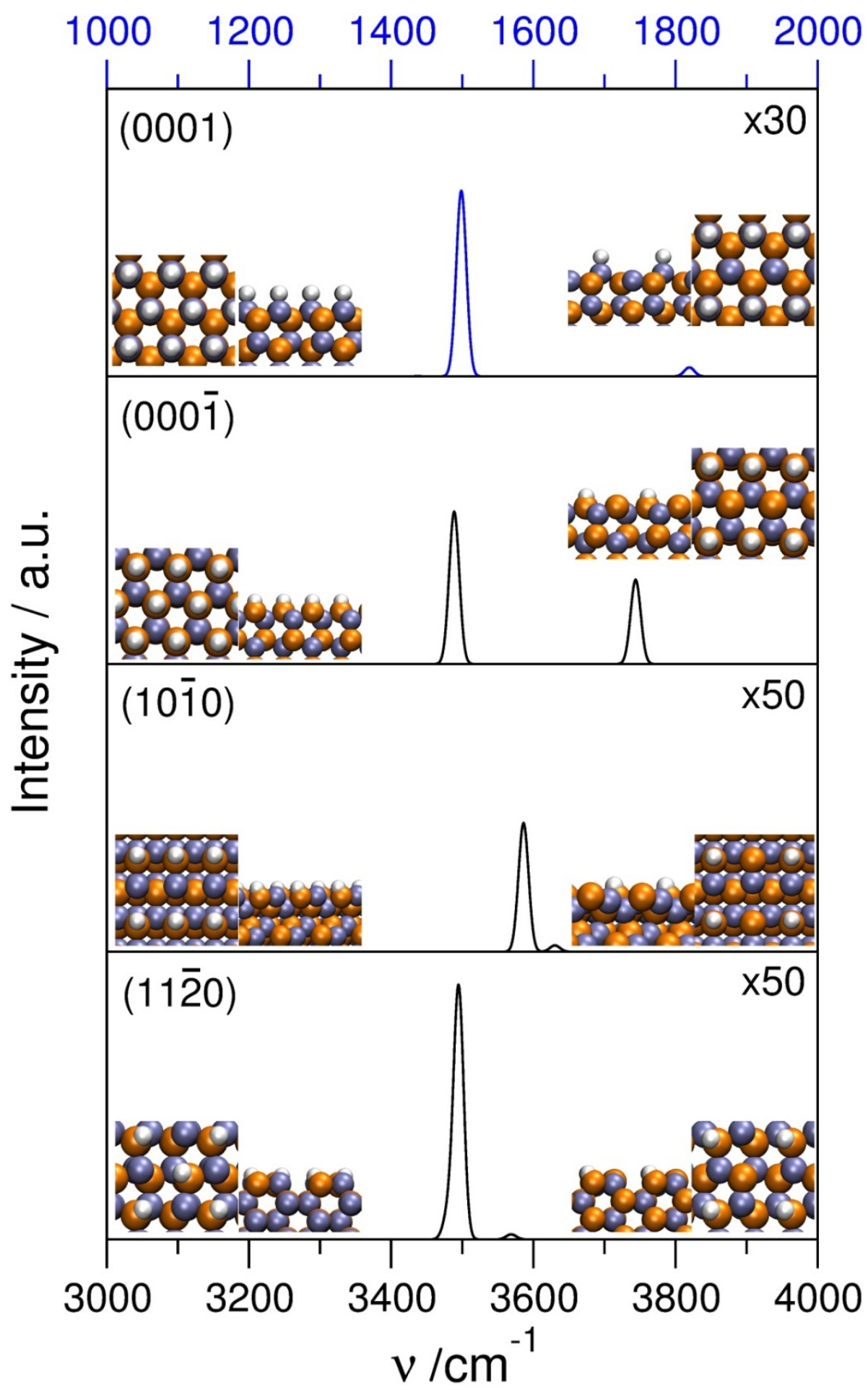


Figure 3: Simulated IR spectra for full $\mathrm{H}$ coverage situation having both $\mathrm{O}_{\mathrm{s}}-\mathrm{H}$ and $\mathrm{Zn}-\mathrm{H}$ moieties on $(10 \overline{1} 0)$ — top panel — and $(11 \overline{2} 0)$ — bottom panel— non-polar surfaces. Note that both intensity scales are twice larger than those on Figure 2. Vibrational frequency values are summarized in Table 1.

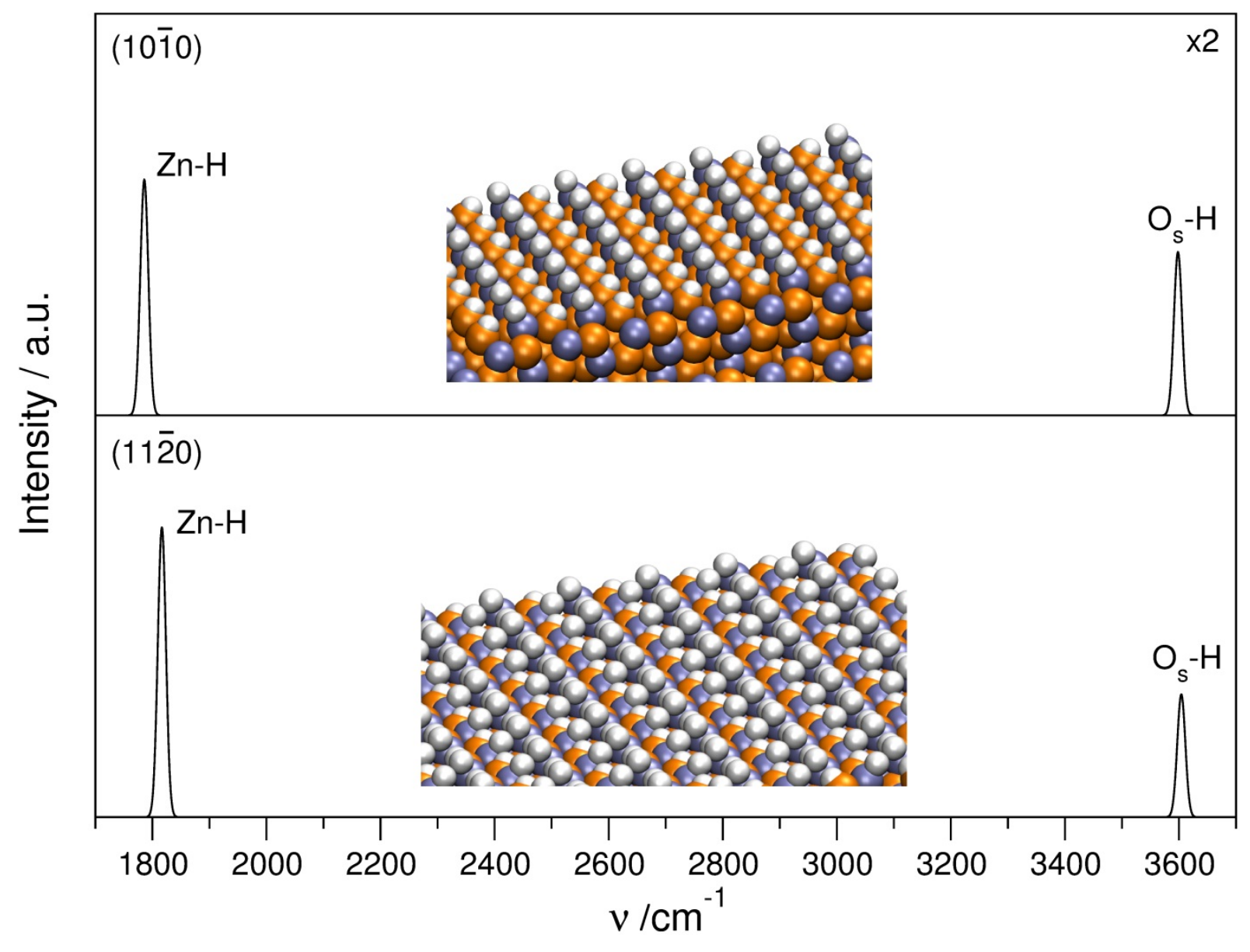


Figure 4: Simulated IR spectra of $\mathrm{OH}$ vibrational frequencies at 0.5 (dashed peaks) and $1 \mathrm{ML}$ (solid peaks) coverages for $(0001),(000 \overline{1}),(10 \overline{1} 0)$, and $(11 \overline{2} 0)$ surfaces. Weak peak intensities have been zoomed by a factor shown at each panel. Blue lines belong to $\mu^{2}$ and $\eta^{2}$ modes. Top and side views of the most IR-intense conformations are displayed in each panel nearby the conformation mode. Vibrational frequencies are gathered in Table 2.

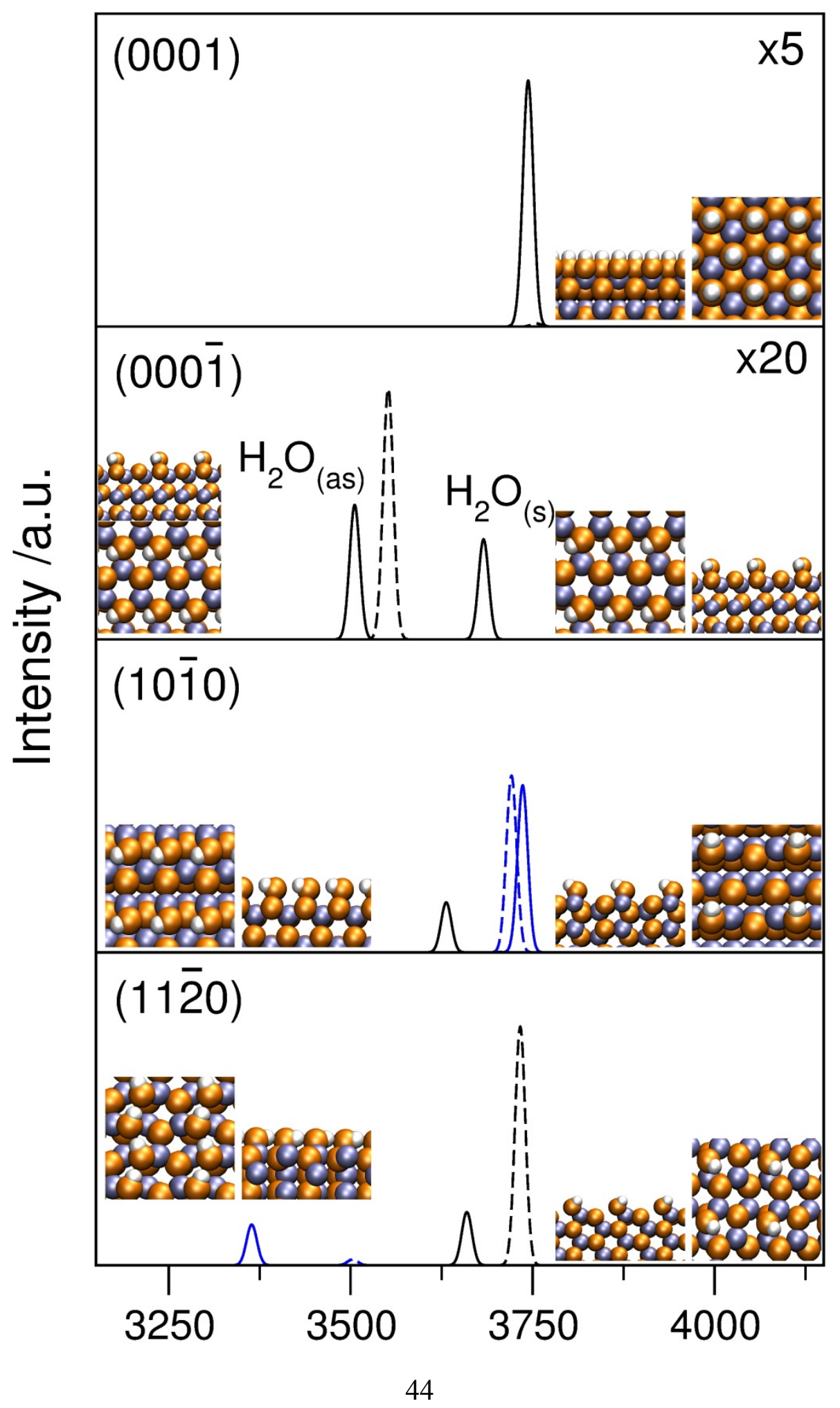


Figure 5: Simulated IR spectra for $\mathrm{OH}$ species at half coverage for polar surfaces and full coverage for $(10 \overline{1} 0)$ and $(11 \overline{2} 0)$ nonpolar surfaces.

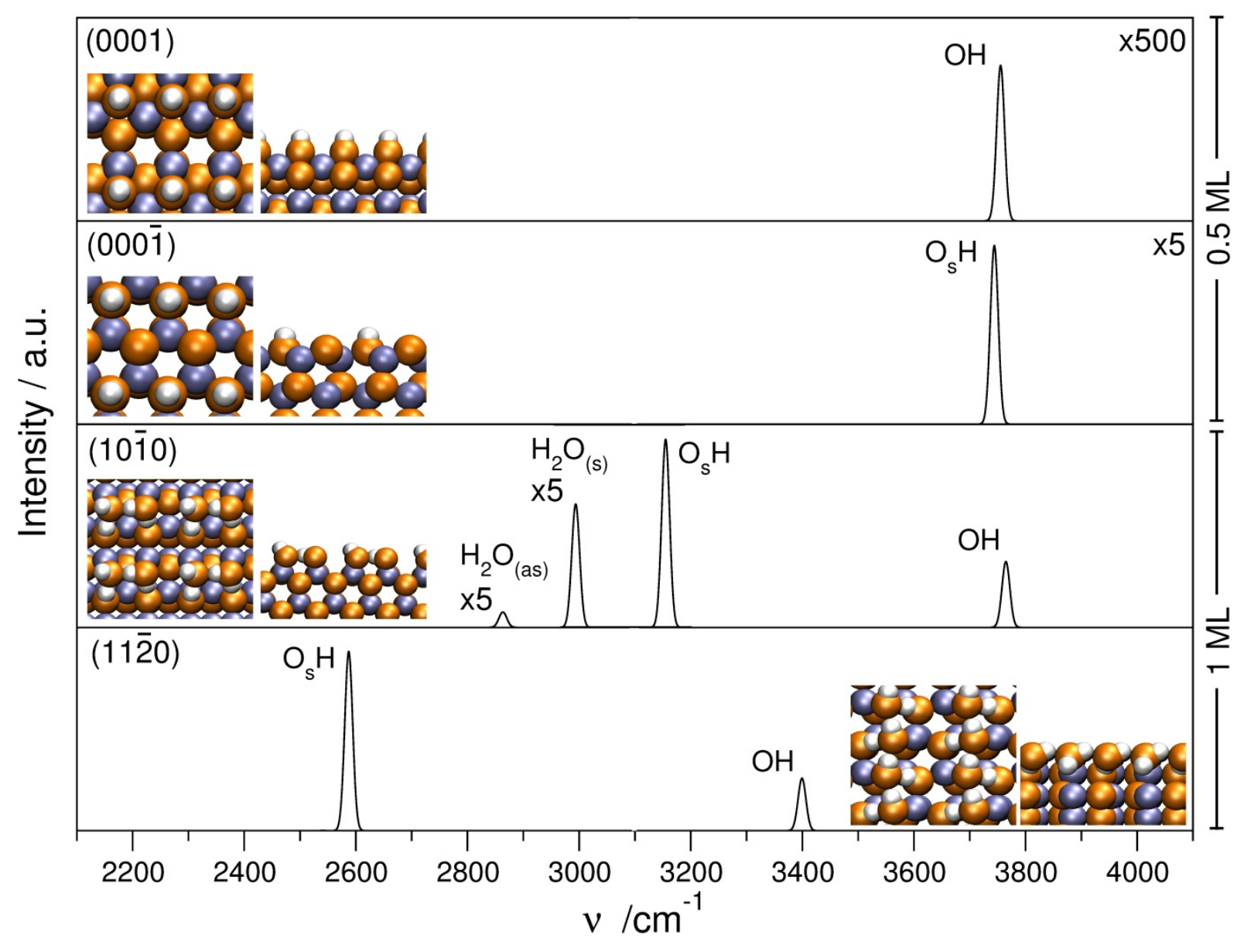


Figure 6: HR-TEM images and FFT diffraction patterns corresponding to samples $\mathbf{A}$ and $\mathbf{B}$.
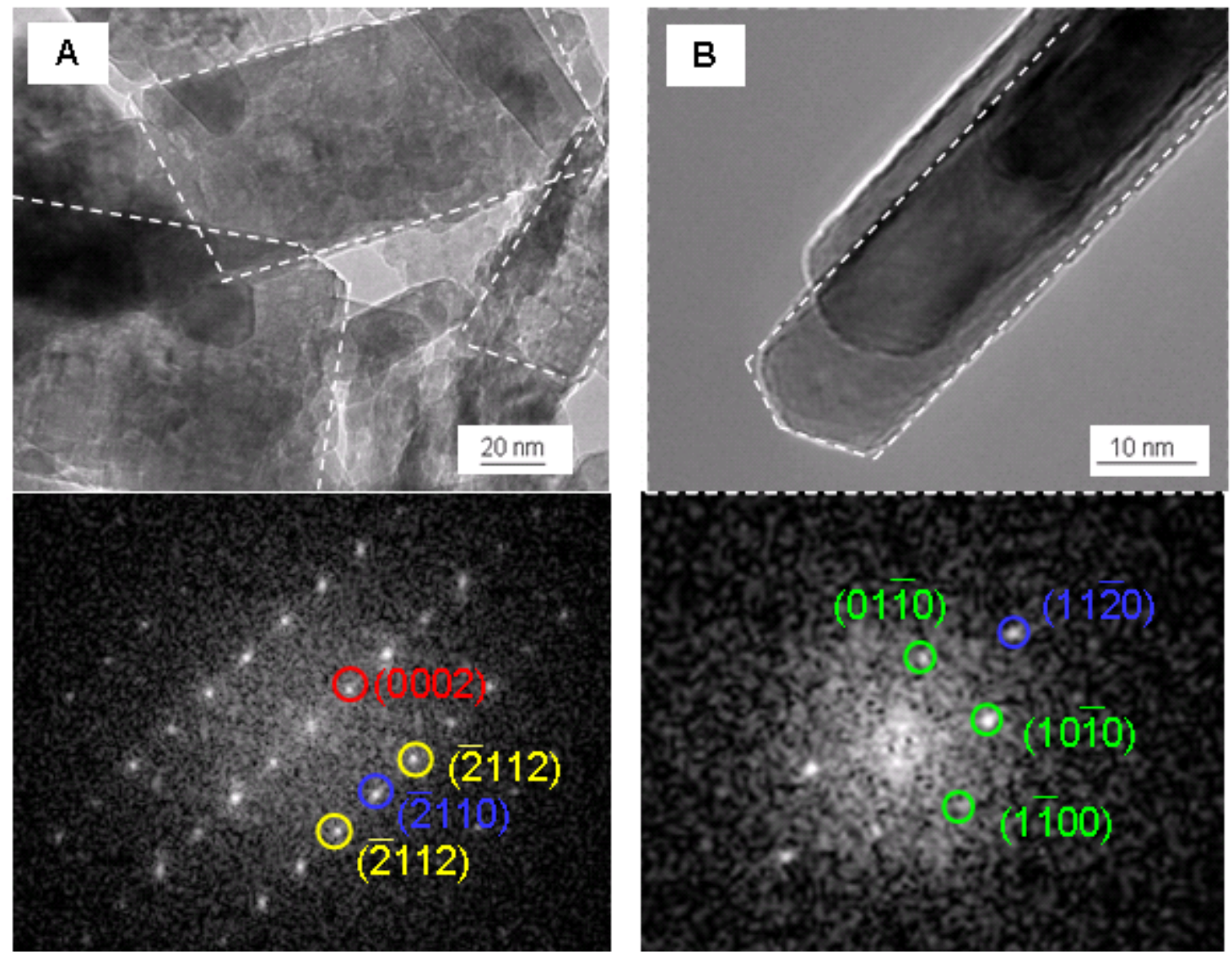
Figure 7: DRIFTS spectra at the hydroxyl region and bands attributable to surface species for samples A (left) and $\mathbf{B}$ (right). A/B sample treated at $150{ }^{\circ} \mathrm{C} ; \mathrm{C} / \mathrm{D}$ samples treated at $350{ }^{\circ} \mathrm{C}$. Colour-code is the same as the used in Figure 1 labelling the surfaces
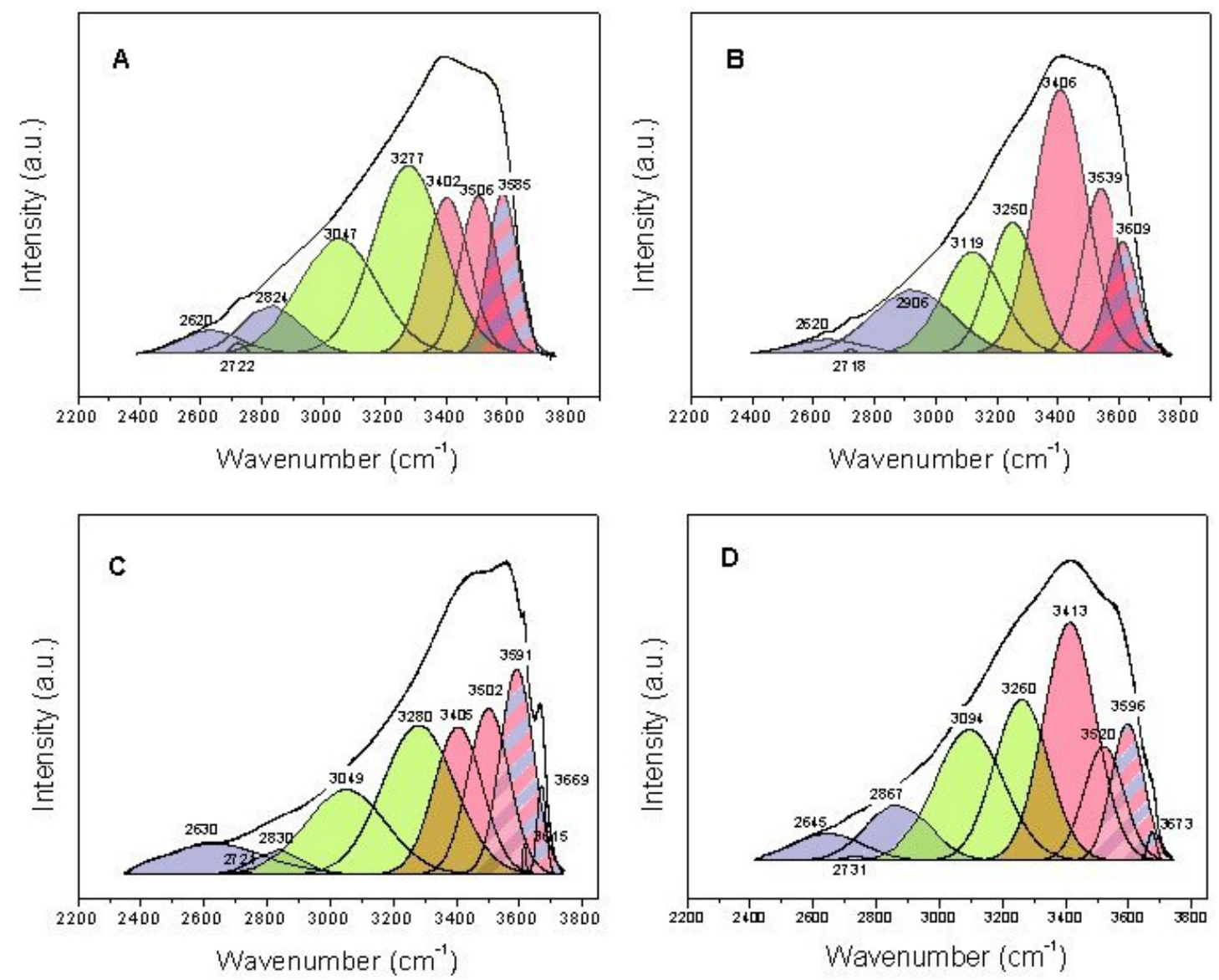
Figure 8: Intensity of the contributions presented in Figure $7 \mathrm{~A} / \mathrm{B}$ and ascription to different surface planes. Colour-code is the same as those in Figure 1 to label the surfaces.

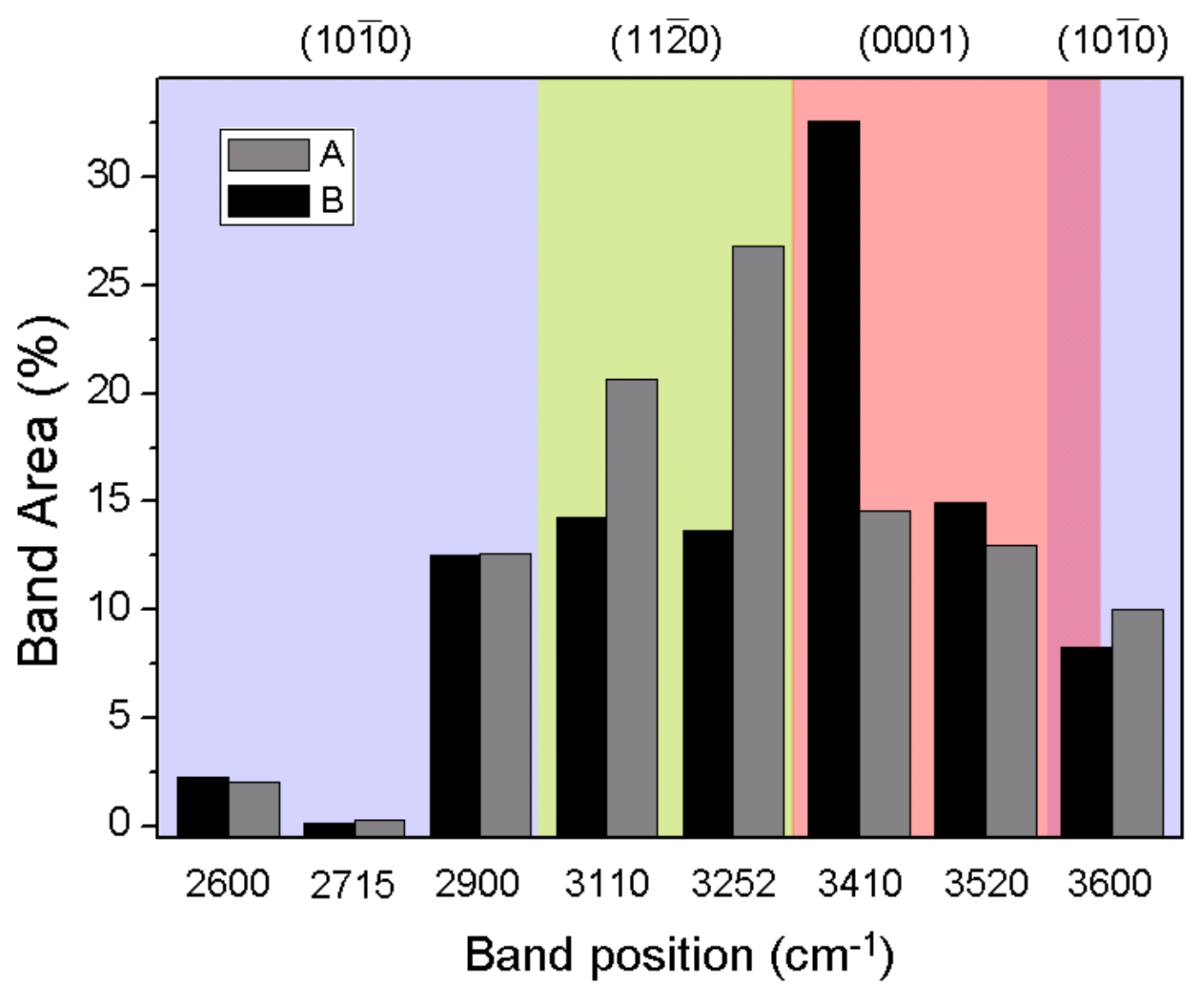


Graphic for Table of Contents (TOC).

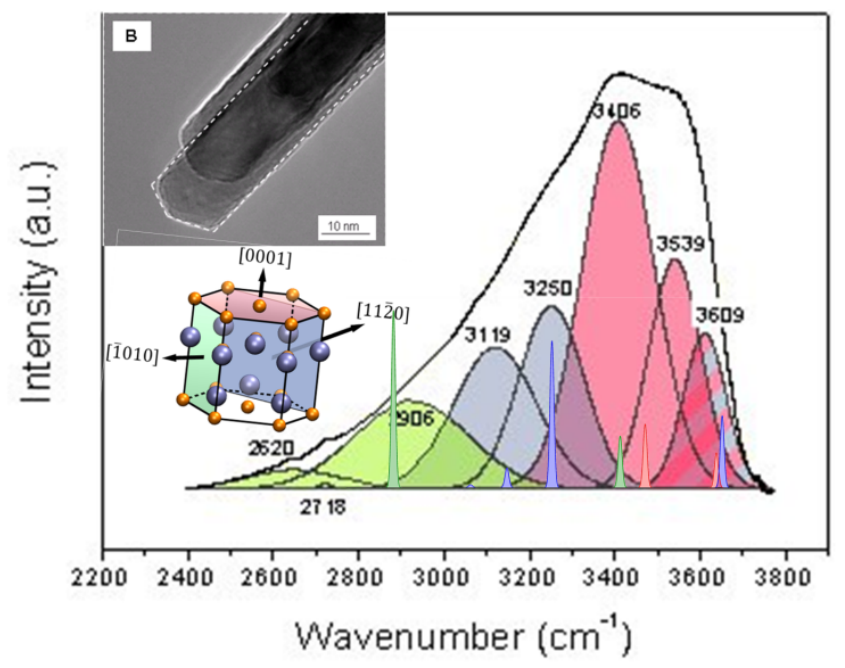

